\title{
A comparison of direct versus self-report measures for assessing physical activity in adults: a systematic review Stéphanie A Prince*1, Kristi B Adamo ${ }^{2,3}$, Meghan E Hamel ${ }^{4}$, Jill Hardt ${ }^{5}$, Sarah Connor Gorber ${ }^{1,5}$ and Mark Tremblay ${ }^{2,6}$
}

\begin{abstract}
Address: ${ }^{1}$ Department of Population Health, University of Ottawa, Ottawa, Ontario, Canada, ${ }^{2}$ Healthy Active Living and Obesity Research Group, Children's Hospital of Eastern Ontario Research Institute, Canada, ${ }^{3}$ Faculty of Health Science, School of Human Kinetics, University of Ottawa, Canada, ${ }^{4}$ Division of Cancer Care and Epidemiology, Cancer Research Institute, Department of Community Health and Epidemiology, Queen's University, Kingston, Ontario, Canada, ${ }^{5}$ Health Information and Research Division, Statistics Canada, Ottawa, Ontario, Canada and 6 Physical Health Measures Division, Statistics Canada, Ottawa, Ontario, Canada
\end{abstract}

Email: Stéphanie A Prince* - sprin063@uottawa.ca; Kristi B Adamo - kadamo@cheo.on.ca; Meghan E Hamel - meghanhamel@gmail.com; Jill Hardt - jillhardt@gmail.com; Sarah Connor Gorber - Sarah.ConnorGorber@statcan.ca; Mark Tremblay - mtremblay@cheo.on.ca

* Corresponding author

Published: 6 November 2008

International Journal of Behavioral Nutrition and Physical Activity 2008, 5:56 doi:10.1186/1479-5868-5-56

This article is available from: http://www.ijbnpa.org/content/5/I/56

(C) 2008 Prince et al; licensee BioMed Central Ltd.

This is an Open Access article distributed under the terms of the Creative Commons Attribution License (http://creativecommons.org/licenses/by/2.0), which permits unrestricted use, distribution, and reproduction in any medium, provided the original work is properly cited.

\begin{abstract}
Background: Accurate assessment is required to assess current and changing physical activity levels, and to evaluate the effectiveness of interventions designed to increase activity levels. This study systematically reviewed the literature to determine the extent of agreement between subjectively (self-report e.g. questionnaire, diary) and objectively (directly measured; e.g. accelerometry, doubly labeled water) assessed physical activity in adults.

Methods: Eight electronic databases were searched to identify observational and experimental studies of adult populations. Searching identified 4,463 potential articles. Initial screening found that 293 examined the relationship between self-reported and directly measured physical activity and met the eligibility criteria. Data abstraction was completed for 187 articles, which described comparable data and/or comparisons, while 76 articles lacked comparable data or comparisons, and a further 30 did not meet the review's eligibility requirements. A risk of bias assessment was conducted for all articles from which data was abstracted.

Results: Correlations between self-report and direct measures were generally low-to-moderate and ranged from $-0.7 \mathrm{I}$ to 0.96 . No clear pattern emerged for the mean differences between self-report and direct measures of physical activity. Trends differed by measure of physical activity employed, level of physical activity measured, and the gender of participants. Results of the risk of bias assessment indicated that $38 \%$ of the studies had lower quality scores.

Conclusion: The findings suggest that the measurement method may have a significant impact on the observed levels of physical activity. Self-report measures of physical activity were both higher and lower than directly measured levels of physical activity, which poses a problem for both reliance on self-report measures and for attempts to correct for self-report - direct measure differences. This review reveals the need for valid, accurate and reliable measures of physical activity in evaluating current and changing physical activity levels, physical activity interventions, and the relationships between physical activity and health outcomes.
\end{abstract}




\section{Background}

Physical activity is defined as "any bodily movement produced by the skeletal muscle that results in energy expenditure (EE)" [1]. Inactivity is known to be associated with an increased risk for many chronic diseases including: coronary artery disease, stroke, hypertension, colon cancer, breast cancer, Type 2 diabetes, and osteoporosis [2], as well as premature death. The economic burden of physical inactivity in Canada has been estimated to be $\$ 2.1$ billion [2]. Physical activity levels are often monitored to assess the health behaviours of the population and their association with health status including mortality and morbidity rates. Accurate assessment of physical activity is required to identify current levels and changes within the population, and to assess the effectiveness of interventions designed to increase activity levels.

Data collection at the population level often involves selfreport (subjective) measures of physical activity through the use of questionnaires, diaries/logs, surveys, and interviews. These measures are frequently used due to their practicality, low cost, low participant burden, and general acceptance [3]. Although self-reports are useful for gaining insight into the physical activity levels of populations, they have the capacity to over- or underestimate true physical activity energy expenditure and rates of inactivity. The self-report methods are often wrought with issues of recall and response bias (e.g. social desirability, inaccurate memory) and the inability to capture the absolute level of physical activity.

As self-report methods possess several limitations in terms of their reliability and validity [4], objective or direct measures of physical activity are commonly used to increase precision and accuracy and to validate the selfreport measures. Direct measures are believed to offer more precise estimates of energy expenditure and remove many of the issues of recall and response bias. Direct measures consist of calorimetry (i.e., doubly labeled water, indirect, direct), physiologic markers (i.e., cardiorespiratory fitness, biomarkers), motion sensors and monitors (i.e., accelerometers, pedometers, heart rate monitors), and direct observation. Despite the advantages of using direct methods, these types of measures are often time and cost intensive and intrusive rendering them difficult to apply to large epidemiologic settings. These measures also require specialized training and the physical proximity of the participant for data collection. In addition, direct measures each possess their own limitations and no single "gold standard" exists for measuring physical activity or assessing validity [3].

The appropriate method for measuring physical activity at various levels depends on factors such as the number of individuals to be monitored, the time period of measure- ments and available finances [5]. Many previous studies have examined the reliability and validity of various selfreport and direct methods for assessing physical activity. Results from these studies have been conflicting. To our knowledge no attempt has been made to synthesize the literature to determine the validity of physical activity measures in adult populations.

The primary objective of this study was to perform a systematic review to compare self-report versus direct measures for assessing physical activity in observational and experimental studies of adult populations. The results from this systematic review provide a comprehensive summary of past research and a comparison between physical activity levels based on direct versus self-report measures in adult populations.

\section{Methods \\ Study criteria}

The review sought to identify all studies (observational or experimental) that presented a comparison of self-report and direct measurement results to reveal differences in physical activity levels based on measurement in adult populations (18 years and over). Studies which examined only a self-report or direct measure, but not both were not included in the review. All study designs were eligible (e.g. retrospective, prospective, case control, randomized controlled trial, etc.) and both published (peer-reviewed) and unpublished literature were examined.

Only studies involving adult populations with a mean age of 18 years and older were considered. Abstracts and titles were examined for their mention of adult populations (using adult\$.tw.), but the search relied mostly on the subject headings for adult age groups (exp adult/). This systematic review was conducted simultaneously with a systematic review of the same focus in child populations (mean age $<19$ years). A separate pediatric review was carried out as a result of differences in measurement methodologies and hypothesized cognitive and recall abilities between adults and children [6].

The eligible self-report measures of physical activity included: diaries or logs; questionnaires; surveys; and recall interviews. Proxy-reports were excluded because they present issues of reliability due to the potential heterogeneity of reporters (e.g., spouse, trainer, coach, parent, caregiver). The eligible direct measures of physical activity included: doubly-labeled water (DLW), indirect or direct calorimetry, accelerometry, pedometry, heart rate monitoring (HRM), global positioning systems, and direct observation. Although no language restrictions were imposed in the search, only English language articles were included in the review. Abstracts were included if they provided sufficient details to meet inclusion criteria. 


\section{Search strategy}

The following electronic bibliographic databases were searched using a comprehensive search strategy to identify relevant studies reporting the use of both self-report and direct measures for assessing individual physical activity levels: Ovid MEDLINE(R) (1950 to April Week 4 2007); Ovid EMBASE (1980 to 2007 Week 18); Ovid CINAHL (1982 to April Week 4 2007); Ovid PsycINFO (1806 to April Week 1 2007); SPORTDiscus (1830 to April 2007); Physical Education Index (1970 to April 2007); Dissertations and Theses (1861 to April 2007); and Ovid MEDLINE (R) Daily Update (May 4, 2007). The search strategy is illustrated using the MEDLINE search as an example (Table 1) and was modified according to the indexing systems of the other databases. The OVID interface was used to search MEDLINE, EMBASE, CINAHL, and PsycINFO; Ebscohost was used to search SPORTDiscus; Scholar's Portal was used to search Physical Education Index; and ProQuest for Dissertations and Theses. Grey literature (non-peer reviewed works) included published abstracts and conference proceedings, published lists of theses and dissertations, and government reports. Knowledgeable researchers in the field were solicited for key studies of interest. The bibliographies of key studies selected for the review were examined to identify further studies.

Two independent reviewers screened the titles and abstracts of all studies to identify potentially-relevant articles. Duplicates were manually removed. The full texts of all studies that met the inclusion criteria were then obtained and reviewed. When disagreements between reviewers occurred, consensus was achieved through discussion and/or with a third reviewer.

Standardized data abstraction forms were completed by one reviewer and verified by two others. Information was extracted on the type of study design, participant characteristics, sample size, and methods of physical activity measurement (self-report and direct measures employed, units of measurement, duration of direct measure, length of recall, and length of time between the self-report and directly measured estimates). Reviewers were not blinded to the authors or journals when extracting data.

\section{Risk of bias assessment}

The Downs and Black [7] checklist was used to assess the risk of bias. The Downs and Black instrument was recommended for assessing risk of bias in observational studies in a recent systematic review [8] and other assessments [9] and was employed in this review to assess study quality including reporting, external validity, and internal validity (bias). The Downs and Black checklist consists of 27 items with a maximum count of 32 points. A modified version of the checklist was employed with items that were not relevant to the objectives of this review removed. The adapted checklist consisted of 15 items, including items $1-4,6,7,9-13,16-18$, and 20 from the original list, with a maximum possible count of 15 points (higher scores indicate superior quality). The risk of bias assessment was carried out by two independent assessors and when disagreements between assessors occurred, consensus was achieved through discussion.

\section{Data synthesis}

Percent mean difference was used as the main outcome of this analysis; it was calculated using the formula: [(selfreport mean - direct mean)/direct mean]. Only studies with units of measurement that were the same for both the self-report and direct measures were used to calculate percent mean differences. Units were converted where possible. These studies were included in the direct comparison analyses. Forest plots (graphical displays of the percent mean differences across the individual studies) were constructed to present overall trends in agreement of physical activity by direct measure and gender. As most studies did not employ the same units of measurement (e.g. kcal/week, MET/day, MET-min/day) and did not report a measure of variance (e.g. standard deviations or standard errors), pooled estimates and confidence intervals were not calculated.

\section{Results}

\section{Description of studies}

The preliminary search of electronic bibliographic databases, reference lists and grey literature identified 4,463 citations (see Figure 1). Of these, 1,638 were identified in MEDLINE, 1,306 in EMBASE, 732 in CINAHL, 218 in PsycINFO, 133 in SportDISCUS, 34 in Physical Education Index, 3 in MEDLINE Daily Update, and 399 from Dissertations and Theses. After a preliminary title and abstract review, 296 full text articles were retrieved for a detailed assessment. Of these, 173 met the criteria for study inclusion. One hundred and forty-eight of these studies reported correlation statistics [10-157]. Seventy-four studies contained comparable data meaning the self-report and direct measurements were reported using the same units $\quad[11,15,17,19,20,23,32,33,44,48,53,56-59,65,73$ $77,80,88,90,92,94,100,102,105,111,114,116,119$ $121,128,131,134,135,138-$ $140,143,148,151,153,154,158-183]$. These studies were included in the direct comparison analyses and their characteristics are described in Table 2. Common reasons for excluding studies included: populations with mean ages less than 18 years, the absence of directly measured and self-report data on the same population, non-English language, duplicate reporting of data, and the absence of comparable units between measures or the absence of a direct comparison. 
Table I: Medline search strategy

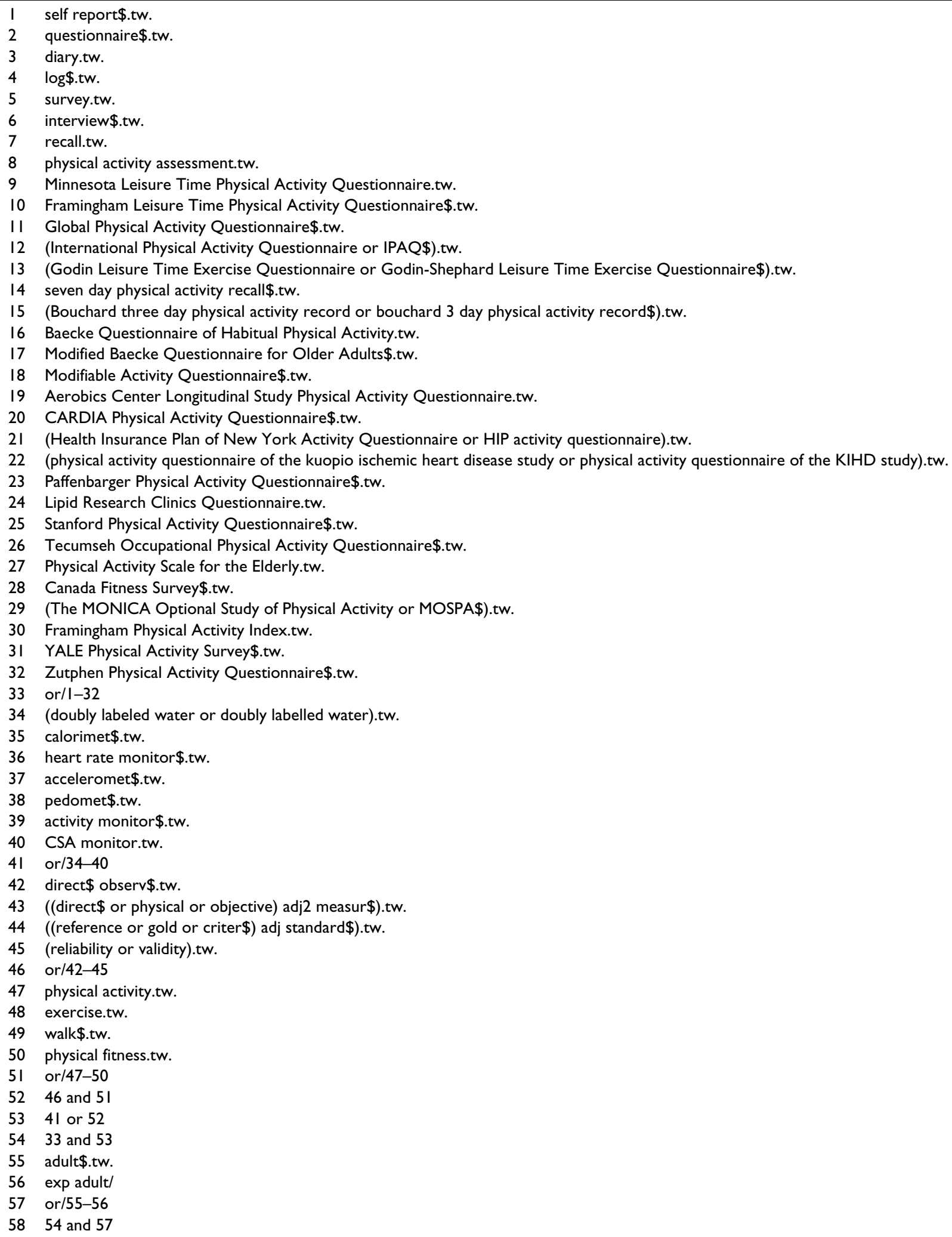


Table 2: Study and participant characteristics for studies with directly comparable data

\begin{tabular}{|c|c|c|c|c|c|c|c|c|c|}
\hline \multirow[t]{2}{*}{ First Author - Year } & \multirow{2}{*}{$\begin{array}{l}\text { Age Range or } \\
\text { Mean (SD) }\end{array}$} & \multicolumn{3}{|c|}{$\mathbf{N}_{\text {analyzed }}$} & \multirow[t]{2}{*}{ Population } & \multirow[t]{2}{*}{ Direct Measure } & \multirow[t]{2}{*}{ Indirect Measure } & \multirow[t]{2}{*}{ Units } & \multirow{2}{*}{$\begin{array}{c}\text { Testing } \\
\text { Conditions* }\end{array}$} \\
\hline & & Total & Men & Women & & & & & \\
\hline Adams $2003 \mathrm{~A}$ & $40-65$ & 80 & 0 & 80 & Disease free & Accel & 7-day PAR - Light & $\mathrm{kcal} / \mathrm{kg} /$ day & A \\
\hline Adams 2003 B & & & & & & Accel & 7-day PAR - MPA & & \\
\hline Adams 2003 C & & & & & & Accel & 7-day PAR - VPA & & \\
\hline Adams $2005 \mathrm{~A}$ & $40-65$ & 80 & 0 & 80 & Disease free & DLW & 7-day PAR I & $\mathrm{kcal} / \mathrm{kg} /$ day & C \\
\hline Adams 2005 B & & & & & & DLW & 7-day PAR 2 & & \\
\hline Adams 2005 C & & & & & & DLW & 24-hr PAR & & \\
\hline Ainsworth $1993 \mathrm{~A}$ & $23-59$ & 75 & 27 & 48 & White collar workers & Accel & 7-day PAR & average MET & NS \\
\hline Ainsworth 1993 B & & & & & & Accel & Tecumseh & & \\
\hline Ainsworth $1993 \mathrm{C}$ & & & & & & Accel & PAR & & \\
\hline Ainsworth 2000 & $20-60$ & 50 & 0 & 50 & Females & Accel & KPAS & MET-min/day & A \\
\hline Atienza 2005 & $60.3(9.1)$ & 15 & 0 & 15 & Filipino American & Accel & 3-day PAD & $\min / 3$-day & $A$ \\
\hline Barnard 2002 & $22-59$ & 15 & 8 & 7 & Healthy volunteers & DLW & MAQ & MJ & NS \\
\hline Bassett 2000 & $25-70$ & 96 & 48 & 48 & General population & Ped & CAQ & kcal/week & D \\
\hline Bernstein 1998 & $35-69$ & 41 & 18 & 23 & General population & HRM & PAFQ & kcal/day & C \\
\hline Bonnefoy 2001 & $66-82$ & 19 & 19 & 0 & Elderly & DLW & QAPSE & $\mathrm{kcal} /$ day & A \\
\hline Boulay 1994 A & $21(5)$ & 15 & 15 & 0 & X-Country skiers & HRM & 3-day PAD & MJ/day & $C$ \\
\hline Boulay 1994 B & $22(1)$ & & & & Controls & HRM & & & \\
\hline Buchowski 1999 A & $20-50$ & 115 & 45 & 70 & Volunteers - Normal & Indirect cal. & $\mathrm{PAD} \leq 2.4 \mathrm{METS}$ & $\mathrm{min} /$ day & A \\
\hline Buchowski 1999 B & & & & & & Indirect cal. & PAD 2.5-4.4 METS & & \\
\hline Buchowski 1999 C & & & & & & Indirect cal. & PAD $\geq 4.5$ METS & & \\
\hline Buchowski I999 D & & & & & Volunteers - Exercise & Indirect cal. & $\mathrm{PAD} \leq 2.4 \mathrm{METS}$ & & \\
\hline Buchowski 1999 E & & & & & & Indirect cal. & PAD 2.5-4.4 METS & & \\
\hline Buchowski $1999 \mathrm{~F}$ & & & & & & Indirect cal. & $\mathrm{PAD} \geq 4.5 \mathrm{METS}$ & & \\
\hline Clark 1994 A & $37.3(3.6)$ & 14 & 0 & 14 & Large eaters & DLW & PAD & MJ/day & $\mathrm{C}$ \\
\hline Clark I994 B & $39.7(2.0)$ & & & & Small eaters & DLW & & & \\
\hline Conway 2002 A & $42(2.3)$ & 24 & 24 & 0 & Feeding study & DLW & Minnesota & $\mathrm{MJ} /$ day & $C$ \\
\hline Conway 2002 B & & & & & & DLW & Tecumseh & & \\
\hline Conway 2002 AA & $41.2(2.0)$ & 24 & 24 & 0 & Feeding study & DLW & PAR & $\mathrm{MJ} /$ day & C \\
\hline Conway 2002 BB & & & & & & DLW & Stanford & & \\
\hline Davis 2004 A & $19-69$ & 62 & 24 & 38 & Obese & Accel & YPAS & kcal/day & NS \\
\hline Davis 2004 B & & & & & & Accel & & $\mathrm{kcal} / \mathrm{kg} /$ day & \\
\hline Davis 2004 C & & & & & Normal weight & Accel & & $\mathrm{kcal} / \mathrm{day}$ & \\
\hline Davis 2004 D & & & & & & Accel & & $\mathrm{kcal} / \mathrm{kg} /$ day & \\
\hline Ekelund $2006 \mathrm{~A}$ & $20-69$ & 185 & 87 & 98 & Swedish adults & Accel & IPAQ - MPA & $\mathrm{min} / \mathrm{day}$ & $A$ \\
\hline Ekelund 2006 B & & & & & & Accel & IPAQ - VPA & & \\
\hline Fogelholm 1998 & $29-46$ & 20 & 0 & 20 & Overwgt premenopause & HRM & PAD & $\min /$ day & A \\
\hline Friedenreich $2006 \mathrm{~A}$ & $35-65$ & 154 & 75 & 79 & Healthy Canadians & Accel & PAQ & MET-hr/week & B \\
\hline Friedenreich 2006 B & & & & & & Accel & 7-day PAR & MET-hr/week & \\
\hline Friedenreich 2006 C & & & & & & Accel & PAQ & hr/week & \\
\hline Friedenreich $2006 \mathrm{D}$ & & & & & & Accel & 7-day PAR & hr/week & \\
\hline Hagfors 2005 & $\begin{array}{c}\text { diet } 58.8(9.9), \\
\text { control } 59.5(8.1)\end{array}$ & 9 & 3 & 6 & Rheumatoid Arthritis & DLW & 3-day PAR & MJ/day & $C$ \\
\hline
\end{tabular}


Table 2: Study and participant characteristics for studies with directly comparable data (Continued)

\begin{tabular}{|c|c|c|c|c|c|c|c|c|c|}
\hline Hayden-Wade $2003 \mathrm{~A}$ & $18-67$ & 69 & 25 & 44 & Active and sedentary & Accel & 7-day PAR - MPA & $\mathrm{min} /$ week & $\mathrm{A}$ \\
\hline Hayden-Wade 2003 B & & & & & & Accel & 7-day PAR - Hard & & \\
\hline Hayden-Wade 2003 C & & & & & & Accel & 7-day PAR - Vhard & & \\
\hline lqbal $2006 \mathrm{~A}$ & $26(3.8)$ & 50 & 0 & 50 & Pakistani & Accel & MOSPA - LT & $\mathrm{kcal} /$ day & $A$ \\
\hline Iqbal 2006 B & & & & & & Accel & MOSPA - ST & & \\
\hline Irwin 200 I A & $27-65$ & 24 & 24 & 0 & Adult men & DLW & 7-day PAR & $\mathrm{kcal} /$ day & C \\
\hline Irwin 200I B & & & & & & DLW & PAL & & \\
\hline Jacobs Jr 1993 A & $20-59$ & 78 & 28 & 50 & & Accel & Minnesota & $\mathrm{MET} / \mathrm{min} / \mathrm{day}$ & NS \\
\hline Jacobs Jr 1993 B & & & & & & Accel & 7-day PAR & & \\
\hline Jacobs Jr 1993 C & & & & & & Accel & CAQ & & \\
\hline Jakicic 1998 A & $25-50$ & 50 & 0 & 50 & Overwgt under reporters & Accel & PAR & $\mathrm{min} /$ week & $A$ \\
\hline Jakicic 1998 B & & & & & Overwgt over reporters & Accel & PAR & & \\
\hline Johnson Kozlow 2006 A & $35-77$ & 96 & 0 & 96 & Breast cancer & Accel & IPAQ & $\mathrm{min} /$ week & A \\
\hline Johnson Kozlow 2006 B & & 63 & 0 & 63 & & & 7-day PAR & & \\
\hline Johnson-Kozlow 2007 & $38-72$ & 63 & 0 & 63 & Breast cancer & Accel & WHIQ & $\mathrm{min} /$ week & $A$ \\
\hline Koulouri $2006 \mathrm{~A}$ & $28.3(6.0)$ & 10 & & & Healthy - baseline & Ped & PAD & $\mathrm{KJ}$ & A \\
\hline Koulouri 2006 B & & & & & Healthy - intervention & Ped & & & \\
\hline Lasuzzo 2004 & 71.7 (8.2) & 39 & 19 & 20 & Seniors & Accel & Fullerton & MET-min/day & $A$ \\
\hline Leenders 1998 A & $18-40$ & 10 & 0 & 10 & Healthy females & Accel, HRM, DLW & 7-day PAR & $\mathrm{kcal} /$ day & $A$ \\
\hline Leenders 1998 B & & & & & & Accel, DLW & PAEE & $\mathrm{kcal} / \mathrm{day}$ & \\
\hline Leenders 2000 & $26(6.6)$ & 12 & 0 & 12 & Healthy college & Accel, Ped & 7-day PAR & $\mathrm{kcal} / \mathrm{kg} /$ day & A \\
\hline Leenders 200I & $21-37$ & 13 & 0 & 13 & Healthy females & Accel, Ped, DLW & 7-day PAR & $\mathrm{kcal} / \mathrm{day}$ & $A$ \\
\hline Lemmer $2001 \mathrm{~A}$ & $20-30$ & 40 & 21 & 19 & Younger males & Accel & PAQ & kJ/day & $\mathrm{C}$ \\
\hline Lemmer 200I B & $65-75$ & & & & Older males & Accel & & & \\
\hline Levin $1999 \mathrm{~A}$ & $21-59$ & 77 & 28 & 49 & Healthy volunteers & Accel & 4-week PAR & MET-min/day & C \\
\hline Levin 1999 B & & & & & & & SAFE & & \\
\hline Liu 2001 & $22-86$ & 31 & & & Elderly Chinese & Indirect cal. & PAQ & kcal & NS \\
\hline Lof $2003 \mathrm{~A}$ & $2|-4|$ & 34 & 0 & 34 & Healthy Swedish & Accel, HRM, DLW & $\mathrm{PAQ}-\mathrm{TEE}$ & kJ/24-hour & $A$ \\
\hline Lof 2003 B & & & & & & HRM & PAQ - PAEE & & \\
\hline Lovejoy 200I A & $47.4(0.2)$ & 149 & 0 & 149 & Premenopausal African & Accel & PAQ & $\mathrm{kJ} /$ day & $\mathrm{D}$ \\
\hline Lovejoy 200I B & & & & & Premenopausal White & Accel & & $\mathrm{kJ} / \mathrm{day}$ & \\
\hline Masse 1999 & $35-61$ & 31 & 0 & 31 & Volunteers & Accel & 3-day PAD & $\mathrm{kcal} /$ day & $A$ \\
\hline Matthews 1995 A & 26.7 & 25 & 14 & 11 & University volunteers & Accel & 3-day PAL & $\mathrm{kcal} / \mathrm{day}$ & A \\
\hline Matthews 1995 B & & & & & & & 7-day PAR & & \\
\hline Matthews $2005 \mathrm{~A}$ & 46 & 69 & & & Volunteers & Accel & 24-hr PAR & $\min /$ day & $\mathrm{C}$ \\
\hline Matthews 2005 B & & & & & & Accel & & $\mathrm{min} / \mathrm{wk}$ & \\
\hline Matthews $2005 \mathrm{C}$ & & & & & & Accel & STAR Closed & $\min /$ day & \\
\hline Matthews $2005 \mathrm{D}$ & & & & & & Accel & & $\mathrm{min} / \mathrm{wk}$ & \\
\hline Matthews $2005 \mathrm{E}$ & & & & & & Accel & STAR Open & $\min /$ day & \\
\hline Matthews $2005 \mathrm{~F}$ & & & & & & Accel & & $\mathrm{min} / \mathrm{wk}$ & \\
\hline McDermott $2000 \mathrm{~A}$ & $67.2(7.0)$ & $4 \mid$ & 19 & 22 & Peripheral Arterial Disease & Accel & LTPAQ & $\mathrm{kcal} /$ week & $A$ \\
\hline McDermott 2000 B & $66.1(5.4)$ & & & & Non-PAD & Accel & & & \\
\hline Meriwether 2006 A & $20-61$ & 63 & 10 & 58 & Volunteers & Accel & PAAT & $\mathrm{min} /$ week & $A$ \\
\hline Meriwether 2006 B & & & & & & Accel & IPAQ & & \\
\hline Miller 2005 A & $61.6(7.2)$ & 13 & & & Diabetic/CABG intervention & Accel & 7-day PAD & $\mathrm{kcal} / \mathrm{kg} /$ day & $\mathrm{D}$ \\
\hline Miller 2005 B & & & & & Diabetic/CABG control & Accel & & & \\
\hline Paton 1996 & $26-45$ & 10 & 10 & 0 & HIV positive & DLW & PAD & PA Level & A \\
\hline
\end{tabular}




\begin{tabular}{|c|c|c|c|c|}
\hline Paul 2005 & $39(9)$ & 12 & 12 & 0 \\
\hline Pitta $2005 \mathrm{~A}$ & $61(8)$ & 13 & 10 & 3 \\
\hline \multicolumn{5}{|l|}{ Pitta 2005 B } \\
\hline \multicolumn{5}{|l|}{ Pitta 2005 C } \\
\hline \multicolumn{5}{|l|}{ Pitta $2005 \mathrm{D}$} \\
\hline \multicolumn{5}{|l|}{ Pitta 2005 E } \\
\hline Racette $1995 \mathrm{~A}$ & $21-47$ & 14 & 0 & 14 \\
\hline \multicolumn{5}{|l|}{ Racette 1995 B } \\
\hline Richardson 1994 A & $20-59$ & 78 & 28 & 50 \\
\hline \multicolumn{5}{|l|}{ Richardson 1994 B } \\
\hline \multicolumn{5}{|l|}{ Richardson 1994 C } \\
\hline Richardson 1995 & $20-59$ & 78 & 28 & 50 \\
\hline Richardson 200I & $20-59$ & 77 & 27 & 50 \\
\hline Rothenberg 1998 & 73 & 20 & 8 & 12 \\
\hline Rutgers 1997 A & $68-78$ & 13 & 0 & 13 \\
\hline \multicolumn{5}{|l|}{ Rutgers 1997 B } \\
\hline Schmidt $2003 \mathrm{~A}$ & $39-65$ & 58 & 0 & 58 \\
\hline \multicolumn{5}{|l|}{ Schmidt 2003 B } \\
\hline \multicolumn{5}{|l|}{ Schmidt 2003 C } \\
\hline Schmidt 2006 A & $18-47$ & 54 & 0 & 54 \\
\hline \multicolumn{5}{|l|}{ Schmidt 2006 B } \\
\hline \multicolumn{5}{|l|}{ Schmidt 2006 C } \\
\hline Schulz 1989 A & $20-30$ & 6 & 4 & 2 \\
\hline \multicolumn{5}{|l|}{ Schulz 1989 B } \\
\hline \multicolumn{5}{|l|}{ Schulz I989 C } \\
\hline \multicolumn{5}{|l|}{ Schulz I989 D } \\
\hline \multicolumn{5}{|l|}{ Schulz 1989 E } \\
\hline \multicolumn{5}{|l|}{ Schulz 1989 F } \\
\hline \multicolumn{5}{|l|}{ Schulz 1989 G } \\
\hline \multicolumn{5}{|l|}{ Schulz I989 H } \\
\hline \multicolumn{5}{|l|}{ Schulz I989 I } \\
\hline \multicolumn{5}{|l|}{ Schulz I989 J } \\
\hline Seale $2002 \mathrm{~A}$ & $67-82$ & 27 & 14 & 13 \\
\hline \multicolumn{5}{|l|}{ Seale 2002 B } \\
\hline \multicolumn{5}{|l|}{ Seale 2002 C } \\
\hline Sjostrom $2002 \mathrm{~A}$ & $4 I(10)$ & 445 & 202 & 243 \\
\hline Sjostrom 2002 B & & & & \\
\hline Sobngwi 2001 & 19-68 & 89 & 44 & 45 \\
\hline Soundy 2005 A & $52.9(9.0)$ & 9 & & \\
\hline Soundy 2005 B & & & & \\
\hline Starling 1998 & $52-79$ & 65 & 28 & 37 \\
\hline Starling 1999 A & $45-84$ & 67 & 32 & 35 \\
\hline Starling 1999 B & & & & \\
\hline Staten $2001 \mathrm{~A}$ & $31-60$ & 35 & 0 & 35 \\
\hline Staten 200I B & & & & \\
\hline Stein 2003 A & $30.6(4.7)$ & 56 & 0 & 56 \\
\hline Stein 2003 B & $27.9(5.4)$ & & & \\
\hline
\end{tabular}

Non-smoking
COPD - Walking
COPD - Cycling
COPD - Standing
COPD - Sitting
COPD - Lying
Obese
Healthy
Healthy
Healthy
Healthy, free-living
Elderly - individual calibration
Elderly - group calibration
College - Freedson
College - Hendelman
College - Swartz
Pregnant - Freedson
Pregnant - Hendelman
Pregnant - Swartz
Healthy university
Pregnant - sedentary
Sedentary
Older free-living
Cevere mental illness
Sural elderly

DLW
Accel
Accel
Accel
Accel
Accel
HRM, DLW
HRM
Accel
Accel
Accel
Accel
Accel
HRM, DLW
HRM
HRM
Accel
Accel
Accel
Accel
Accel
Accel
HRM - Proc I
HRM - Proc 2
HRM - Proc 3
HRM - Proc 4
HRM - Proc I
HRM - Proc 2
HRM - Proc 3
HRM - Proc 4
DLW
DLW
DLW
DLW
DLW
Accel
Accel
Accel
Accel
Accel
DLW
Accel, DLW
Accel
DLW
DLW
Accel, HRM
Accel, HRM

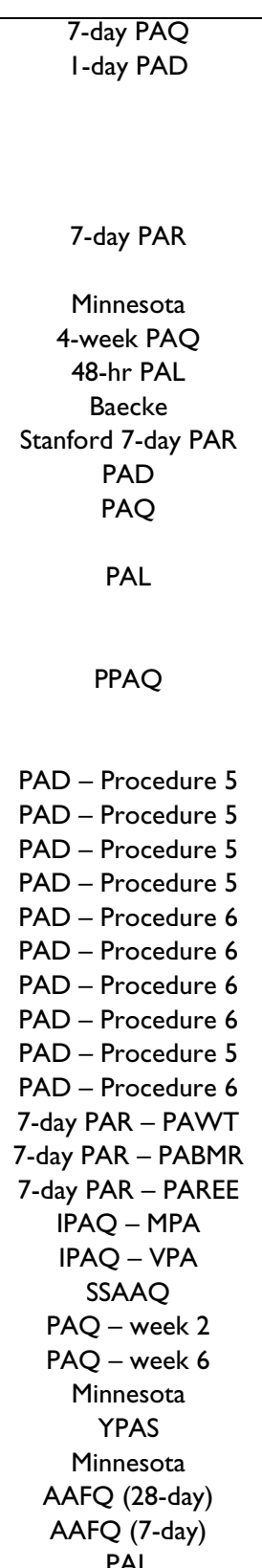

MJ/day

mins.

Stein 2003 B

$27.9(5.4)$

PAL 
Table 2: Study and participant characteristics for studies with directly comparable data (Continued)

\begin{tabular}{|c|c|c|c|c|c|c|c|c|c|}
\hline Strath $2003 \mathrm{~A}$ & $20-56$ & 25 & 12 & 13 & General population & Accel & CAQ - MPA & $\mathrm{min} /$ day & $\mathrm{A}$ \\
\hline Strath 2003 B & & & & & & Accel & CAQ - VPA & & \\
\hline Strath $2003 \mathrm{C}$ & & & & & & Accel & $C A Q-M P A+V P A$ & & \\
\hline Strath 2004 & $20-65$ & 15 & 12 & 14 & General population & Accel & CAQ (with HR) & MET-min/wk & NS \\
\hline Taylor I 984 A & $34-69$ & 12 & 12 & 0 & White males & Accel & Stanford & kcal/day & NS \\
\hline Taylor 1984 B & & & & & & Accel & & $\mathrm{kcal} / \mathrm{kg} /$ day & \\
\hline Taylor $1984 \mathrm{C}$ & & & & & & Accel & PAD & $\mathrm{kcal} /$ day & \\
\hline Taylor I984 D & & & & & & Accel & & $\mathrm{kcal} / \mathrm{kg} /$ day & \\
\hline Timperio $2003 \mathrm{~A}$ & M 37.8 (I2.7), & 122 & 55 & 63 & Overweight & Accel & PAQ > 3 MET & $\min /$ day & A \\
\hline Timperio 2003 B & F $39.6(17.0)$ & & & & & Accel & PAQ 3-5.9 MET & & \\
\hline Timperio $2003 \mathrm{C}$ & & & & & & Accel & PAQ > 6 MET & & \\
\hline Timperio $2004 \mathrm{~A}$ & $18-75$ & 551 & 241 & 310 & Free-living & Accel & AAS - Log & $\min /$ day & A \\
\hline Timperio 2004 B & & & & & & Accel & AAS - No log & & \\
\hline Timperio $2004 \mathrm{C}$ & & & & & & Accel & IPAQ-S - Log & & \\
\hline Timperio $2004 \mathrm{D}$ & & & & & & Accel & IPAQ-S - No log & & \\
\hline Timperio $2004 \mathrm{E}$ & & & & & & Accel & IPAQ-L - Log & & \\
\hline Timperio $2004 \mathrm{~F}$ & & & & & & Accel & IPAQ-L - No log & & \\
\hline Timperio $2004 \mathrm{G}$ & & & & & & Accel & BRFSS - Log & & \\
\hline Timperio $2004 \mathrm{H}$ & & & & & & Accel & BRFSS - No log & & \\
\hline Tzetzis 200I & $|9-2|$ & 75 & 33 & 42 & Novice skiers & HRM & PAQ & time/task & B \\
\hline Wadsworth 2006 A & $18-24$ & 71 & 0 & 71 & College - controls & Accel & IPAQ - MPA & $\mathrm{min} /$ day & A \\
\hline Wadsworth 2006 B & & & & & College - controls & Accel & IPAQ - VPA & & \\
\hline Wadsworth 2006 C & & & & & College - intervention & Accel & IPAQ - MPA & & \\
\hline Wadsworth 2006 D & & & & & College - intervention & Accel & IPAQ - VPA & & \\
\hline Walsh $2004 \mathrm{~A}$ & $20-46$ & 75 & 0 & 75 & Overweight White & DLW & Tecumseh & $\mathrm{kcal} /$ day & NS \\
\hline Walsh 2004 B & & & & & Overweight Black & DLW & & & \\
\hline Walsh 2004 C & & & & & Control White & DLW & & & \\
\hline Walsh 2004 D & & & & & Control Black & DLW & & & \\
\hline Washburn 2003 & $18-33$ & 46 & 17 & 29 & Sedentary mod obese & DLW & PAR & $\mathrm{kJ} /$ day & C \\
\hline Wendel-Vos 2003 A & $44(6)$ & 50 & 36 & 14 & Healthy bank workers & Accel & PAQ 2-4 MET & MET & D \\
\hline Wendel-Vos 2003 B & & & & & & Accel & PAQ 4-6.5 MET & & \\
\hline Wendel-Vos 2003 C & & & & & & Accel & PAQ 6.5+ MET & & \\
\hline Wickel 2006 & $18-23$ & 70 & 13 & 57 & University & Accel & PAD & $\mathrm{kcal} /$ day & A \\
\hline Wilbur 200I A & $45-65$ & 156 & 0 & 156 & Healthy employees & HRM & PAQ & $\mathrm{min} /$ walk & A \\
\hline Wilbur 200I B & & & & & & HRM & PAL & & \\
\hline
\end{tabular}

* A - measuring same length of time (e.g. 7-days, I week) and no time lag, B - same length with time lag, C - different length with no time lag, D - different length with a time lag, NS - not stated Abbreviations: AAFQ - Arizona Activity Frequency Questionnaire, AAS - Active Australia Survey, Accel. - accelerometer, BRFSS - Behavioral Risk Factor Surveillance System, Cal. - calorimetry, CABG - Coronary Artery Bypass Graft, CAQ - College Alumnus Questionnaire, COPD - chronic obstructive pulmonary disease, DLW - doubly labeled water, F - female, Fullerton - Fullerton Physical Activity Questionnaire, HRM - heart rate monitor, IPAQ - International Physical Activity Questionnaire, kcal - kilocalorie, kJ - kilojoules, KPAS - Kaiser Physical Activity Survey, LTPAQ - Leisure Time Physical Activity Questionnaire, M - male, MAQ - Modifiable Activity Questionnaire, MET - metabolic equivalent, MJ - mega joules, min - minute, Minnesota - Minnesota Leisure Time Physical Activity Questionnaire, MOSPA - Monica Optional Study of Physical Activity questionnaire, MPS - moderate physical activity, PAAT - Physical Activity Assessment Tool, PAD physical activity diary, PAEE - physical activity energy expenditure, PAFQ - Physical Activity Frequency Questionnaire, PAL - physical activity log, PAQ - physical activity questionnaire, PAR physical activity recall, Ped. - pedometer, SAFE - Survey of Activity, Fitness, and Exercise, SSAAQ - Sub-Saharan Africa Activity Questionnaire, Stanford - Stanford Physical Activity Questionnaire, STAR - Short Telephone-administered Activity Recall, Tecumseh - Tecumseh Community Health Survey, TEE - total energy expenditure, Vhard - very hard, VPA - vigorous physical activity, WHIQ - Women's Health Initiative Questionnaire, wk - week, YPAS - Yale Physical Activity Survey 


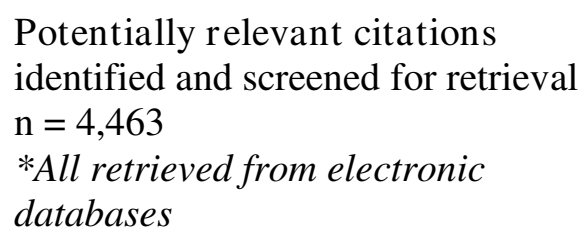

Citations excluded based on abstract and title review $\mathrm{n}=4,170$

Reasons: duplicate retrieval, missing either a direct or indirect measure of physical activity, population mean age under 18 years, or not relevant |

Full text of studies retrieved for more detailed evaluation $n=296$

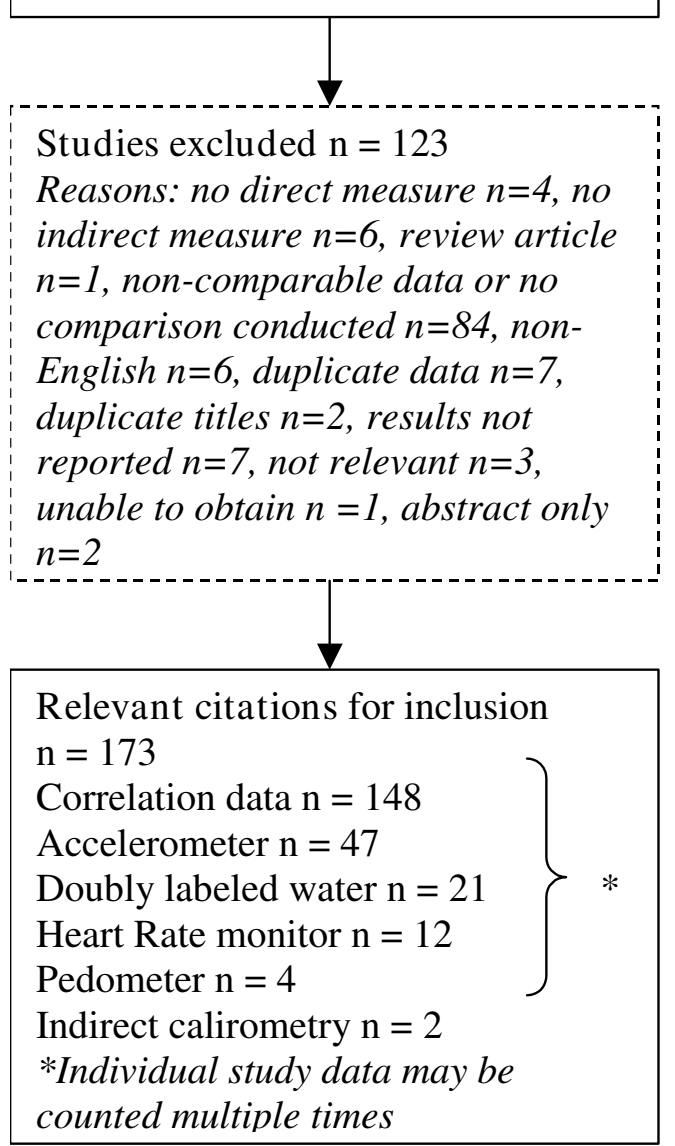

Figure I

Results of the literature search.
Data abstraction identified three articles and two dissertations that analyzed and reported duplicate data in multiple papers [184-188]. Authors of suspected duplications were contacted and in cases where several publications reported the same analyses from the same data source, only one study per data source/analysis was retained in order to avoid double counting. Studies were retained based on the most pertinent and most recent data, as well as the largest sample size. Studies included were published over a 24-year period from 1983 to 2007. All studies were written in English. Nineteen of the studies used randomized controlled trial designs $[22,24,26,28$, $30,50,53,61,84,91,124,148,149,163,165,171,181]$ and all others used observational designs (e.g. case control, cross-sectional, longitudinal). All included studies were published as journal articles except for 19 dissertations $[16,24,30,34,38,45,49,61,64,69,71,73,74,78,99,107,117$ $, 163,171]$.

Participants in the studies ranged from 10 to 101 years of age. Although the focus of the review was on those aged 18 and over, studies that had a range of ages less than 18 years were not excluded as long as the mean age of the sample was over 18 years. Sample sizes ranged from a low of six [21] to a high of 2,721 in Craig et al.'s work that assessed the validity of the International Physical Activity Questionnaire (IPAQ) [35]. There were a greater number of studies reporting on female-only data than studies reporting on male-only data.

A total of five direct measures were used in the assessment of physical activity and included: accelerometers, DLW, indirect calorimetry, HRM, and pedometers. Of the studies included in the synthesis of directly comparable data (Table 2), accelerometers were the most frequently used direct measure and indirect calorimetry was the least used. A variety of self-report measures were employed, but the seven-day physical activity recall (7-day PAR) [189] was the most cited. Over half of the studies reported that the self-report and directly assessed physical activity levels were measured over the same length of time (e.g. seven days) and over the same period of time (i.e. no time lag between measurements). There were also a considerable number who reported measurements over the same period of time, but that did not measure the same length of time (e.g. self-report over seven days, directly measured over three days). Eleven of the studies in Table 2 lacked any mention of time $[59,131,135,138,143,159,160$, $164,177,178,183]$.

\section{Risk of bias assessment}

Risk of bias was assessed for all included studies ( $\mathrm{n}=173)$ including those reporting only correlation data. The range of items met on the modified Downs and Black tool was 8 to 15 (maximum possible count was 15 ) with a mean of 
$11.7 \pm 1.2$. Results of the risk of bias assessment indicated that $38 \%(65 / 173)$ of the studies had lower quality (based on a median split count of $<12 / 15)$. All studies were given maximum points for describing study objectives. All but one study scored maximum points for describing the main outcomes to be measured and the interventions used (including comparison methods between measures). Although most studies carried out some sort of significance testing on results, most did not report the actual probability values associated with the estimates or their associated measures of random variability (e.g. standard error or confidence intervals). Most studies obtained a high number of items on the reporting section (maximum count of 8 ) with a mean of $6.9 \pm 0.9$.

The external validity section of the risk of bias assessment had a maximum count of three and consisted of reporting on the representativenessof the subjects and the testing conditions. Almost all of the studies (166/173) reported that the staff, places and facilities where the participants were tested were representative of the testing conditions that would be expected by most individuals (e.g. real-life and free-living situations). However, 87\% (151/173) of the studies did not report on the representativeness of the subjects asked to participate in the study and 95\% (165/ 173) of the studies failed to report on the representativeness of those who were prepared to participate (enrolled) compared to the entire population from which they were recruited (received a score of 0 ). As a result, the external validity ratings of most studies were poor with a mean of $1.1 \pm 0.5$.

In order to obtain the maximum number of items (four) in the internal validity section, studies must have reported whether any of the results of the study were based on "data dredging", whether the analyses adjusted for any time lag between the two measurements or different lengths of follow-up, whether the statistical tests used to assess the main outcomes were appropriate, and whether the main outcome measures were accurate (valid and reliable). Internal validity item counts were generally high with the majority of studies having obtained a four.

A qualitative analysis was conducted on the top seven (scores of 14 and 15 out of 15) and lowest seven studies ( 8 and 9 out of 15) based on scores from the risk of bias assessment. No conclusive patterns were identified from this analysis. The results from the accelerometer studies were further examined, as this was the only group of studies with a good distribution of low and high quality studies based on the accelerometer median split of bias scores. Findings from this analysis did not identify any clear patterns in the differences in agreement between physical activity measured by self-report compared to accelerometer when grouped by low and high quality.

\section{Data synthesis}

One hundred and forty-eight studies [10,11,13-157,190] reported correlation statistics between self-report and direct measurements of physical activity. Figure 2 is a plot of all extracted correlations and shows that overall, there is no clear trend in the degree of correlation between selfreported and directly measured physical activity, regardless of the direct method employed. Overall, correlations were low-to-moderate with a mean of $0.37(\mathrm{SD}=0.25)$ and a range of -0.71 to 0.98 . Mean correlations were higher in studies reporting results for males-only $(\mathrm{r}=$ 0.47 ) versus studies reporting results for females-only ( $\mathrm{r}=$ 0.36 ), but with very similar ranges (males: -0.17 to 0.93 vs. females: -0.17 to 0.95 ).

Seventy-four studies contained comparable data on the measurement of physical activity based on self-report and directly measured values. Table 2 describes these studies and their subcomponents. Percent mean differences were calculated for all of these studies and are presented as forest plots in Figures 3 to 8 . Negative values indicate that self-report estimates were lower than the amount of physical activity assessed by direct methods while positive values indicate values that are higher. Sixty percent of the percent mean differences indicated that self-reported physical activity estimates were higher than those measured by direct methods.

Studies with extreme percent mean differences $(\geq 400 \%)$ were removed from the forest plots for clarity purposes $[11,139,151,181]$. All outlying data were from studies where physical activity was categorized by level of exertion (e.g. easy, moderate, vigorous) and outliers represent physical activity data categorized as vigorous or of high energy expenditure. While not all data categorized as vigorous had percent mean differences $\geq 400 \%$, a pattern emerged whereby greater percent mean differences between the self-report and direct measures was larger for vigorous levels of physical activity than for light or moderate activities $[11,44,56,134,139,151,175,181,182]$.

Percent mean differences were examined separately for the five different direct measures. Accelerometers were the most used direct measure. Self-report measures of physical activity were generally higher than those directly measured by accelerometers (Figures 3 to 5). Studies reporting data for males and females combined $(n=58)$ had a mean percent difference of $44 \%$ (range: $-78 \%$ to $500 \%$ ), with similar findings for the male-only data $(\mathrm{n}=32)$ (mean: $44 \%$, range: $-100 \%$ to $425 \%$ ). However, female-only data $(n=60)$ identified that, on average, females self-reported higher levels of physical activity compared to accelerometers with a mean percent difference of 138\% (range: $100 \%$ to $4024 \%$ ). 


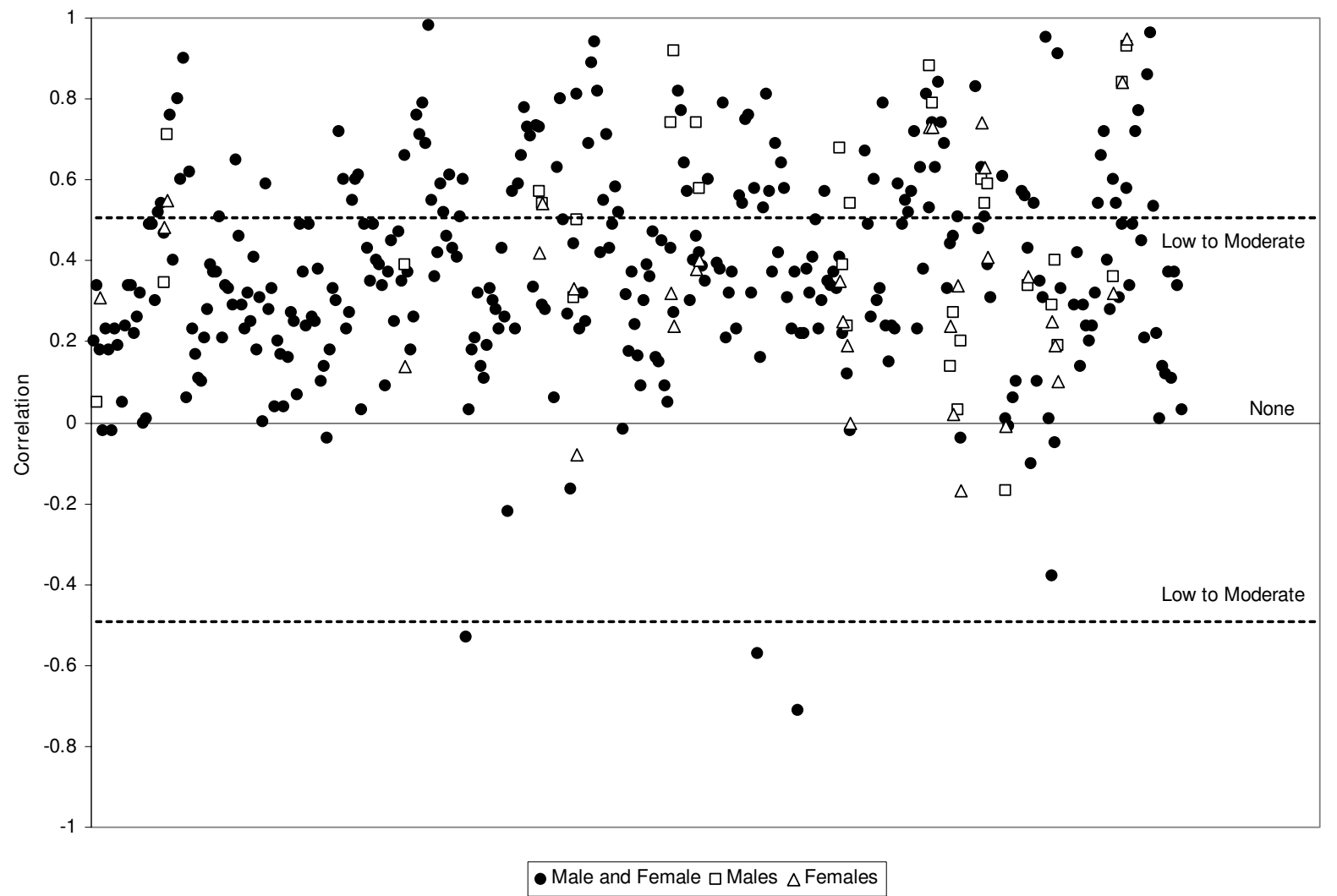

Figure 2

Scatter plot of all correlation coefficients between direct measures and self-report measures.

The second-most common direct measure employed was DLW and comparable data with self-report measures are presented in Figures 6 to 8. Studies reporting on combined male and female data $(n=6)$ indicated that selfreport measures of physical activity were lower when compared to DLW measures with a mean percent difference of $-9 \%$ and a range of $-1 \%$ to $-26 \%$. Results for male-only (n $=16)$ and female-only $(n=23)$ data were less distinct with percent mean differences and ranges of $-4.5 \%(-78 \%$ to $37 \%)$ and $7 \%(-58 \%$ to $113 \%)$, respectively.

A greater number of HRM and self-report comparisons were observed for studies with both male and female participants $(n=11)$ or female-only populations $(n=13)$ versus male-only populations $(\mathrm{n}=3)$. Female-only results showed a general trend toward higher levels of selfreported physical activity (mean $11 \%$, range: $-5 \%$ to $45 \%$ ), while the male-only (mean $-9 \%$, range: $-24 \%$ to $5 \%$ ) and combined (mean $-2 \%$, range: $-21 \%$ to $67 \%$ ) data had a greater number of studies with lower self-reported physical activity levels when compared to results of HRM.
Pedometers and indirect calorimetry were the least commonly used direct measures for studies with comparable data. There were a total of eight comparisons from four studies for pedometers and 15 from two studies for indirect calorimetry (Figures 6 to 8 ) making it difficult to draw conclusions with regard to patterns of agreement between the self-report and direct measures. However, seven $[19,75,76,167]$ of the eight pedometer comparisons reported higher levels of physical activity by self-report when compared to the pedometer results. The eighth comparison [19] which involved female-only data saw no difference between the two measures. The indirect calorimetry results were less straightforward and presented no obvious patterns in agreement.

Subgroups were qualitatively examined to assess whether any differences existed in the degree of agreement between self-reported and directly measured physical activity. No clear patterns emerged within studies reporting on elderly (range or mean $\geq 65$ years) populations $[23,73,77,92,105,116,174]$ or within studies reporting on 


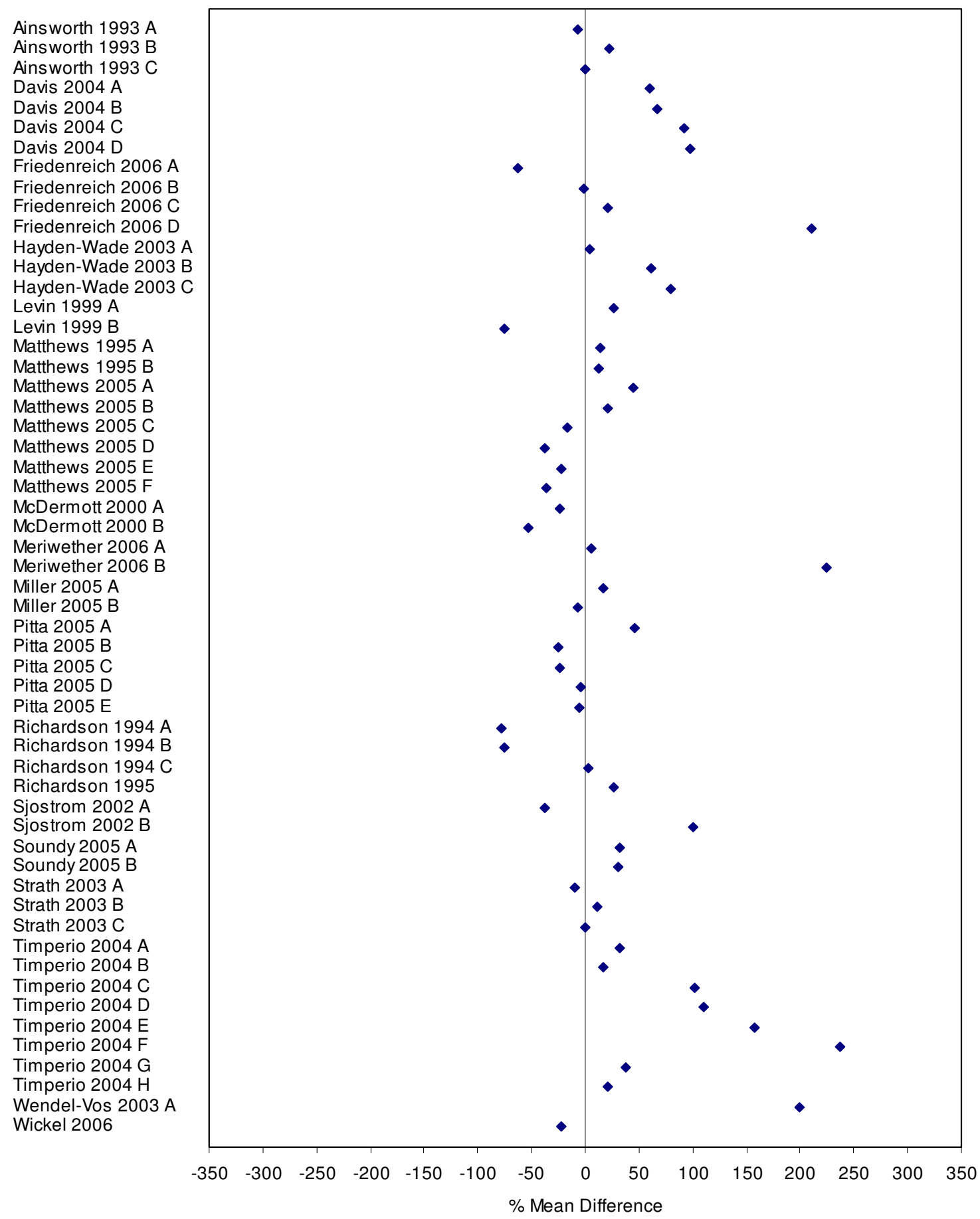

$*$ Values $\geq 400 \%$ are not displayed

Figure 3

Forest plot of percent mean differences between accelerometers and self-report measures from studies reporting combined results for males and females (excluding outliers $\geq 400 \%$ ). 


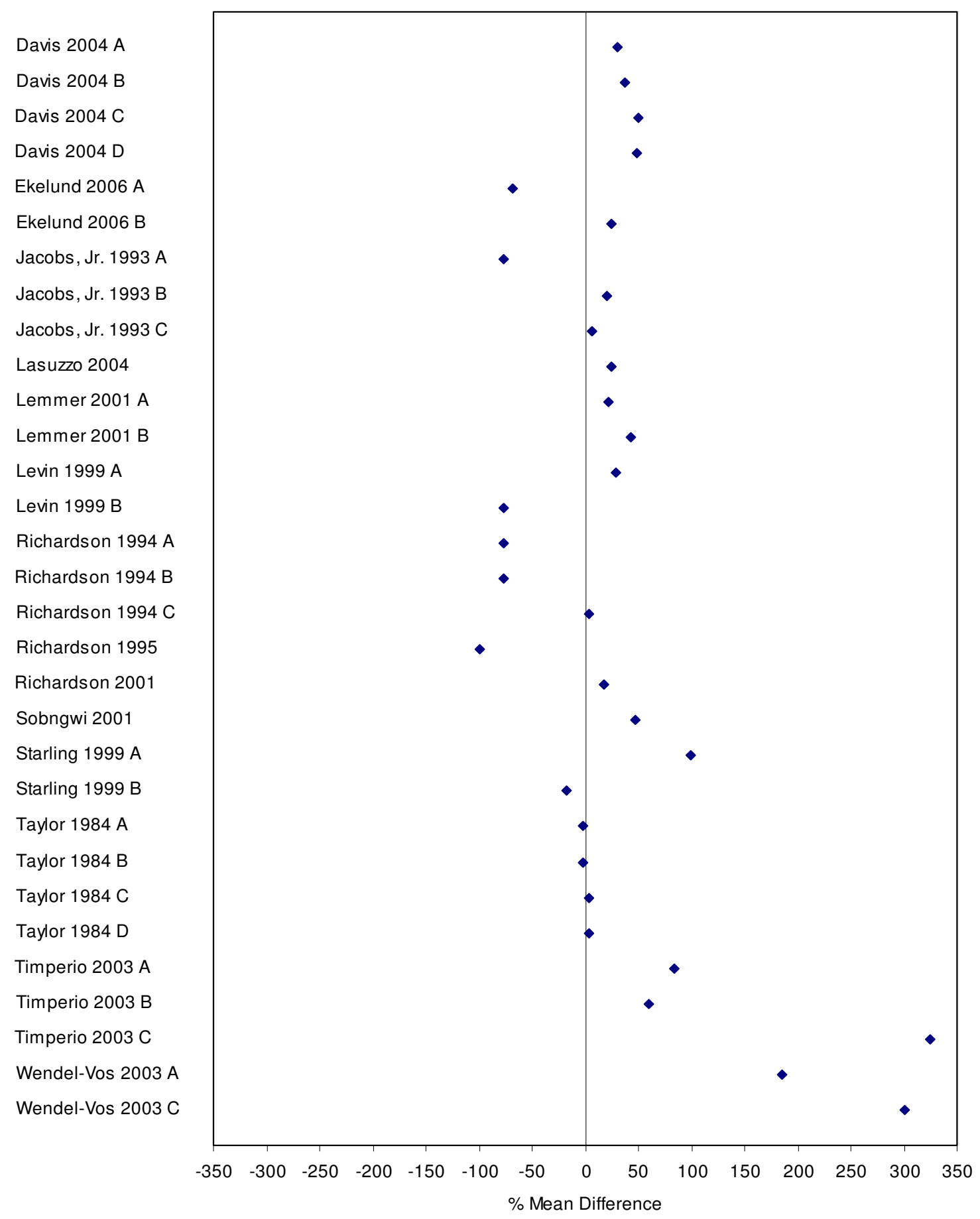

$*$ Values $\geq 400 \%$ are not displayed

Figure 4

Forest plot of percent mean differences between accelerometers and self-report measures from studies reporting results for males only (excluding outliers $\geq 400 \%$ ). 


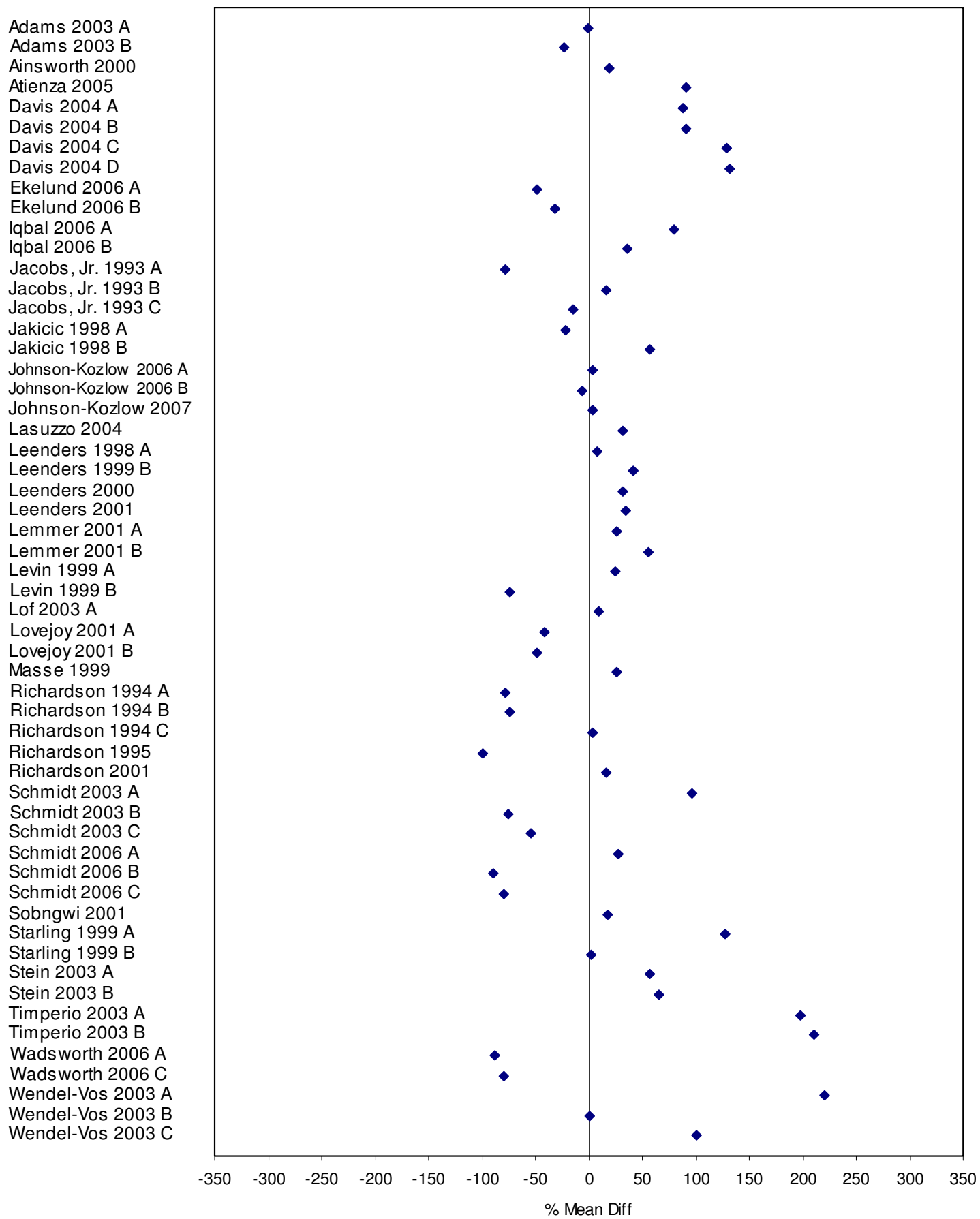

*Values $\geq 400 \%$ are not displayed

Figure 5

Forest plot of percent mean differences between accelerometers and self-report measures from studies reporting results for females only (excluding outliers $\geq 400 \%$ ). 


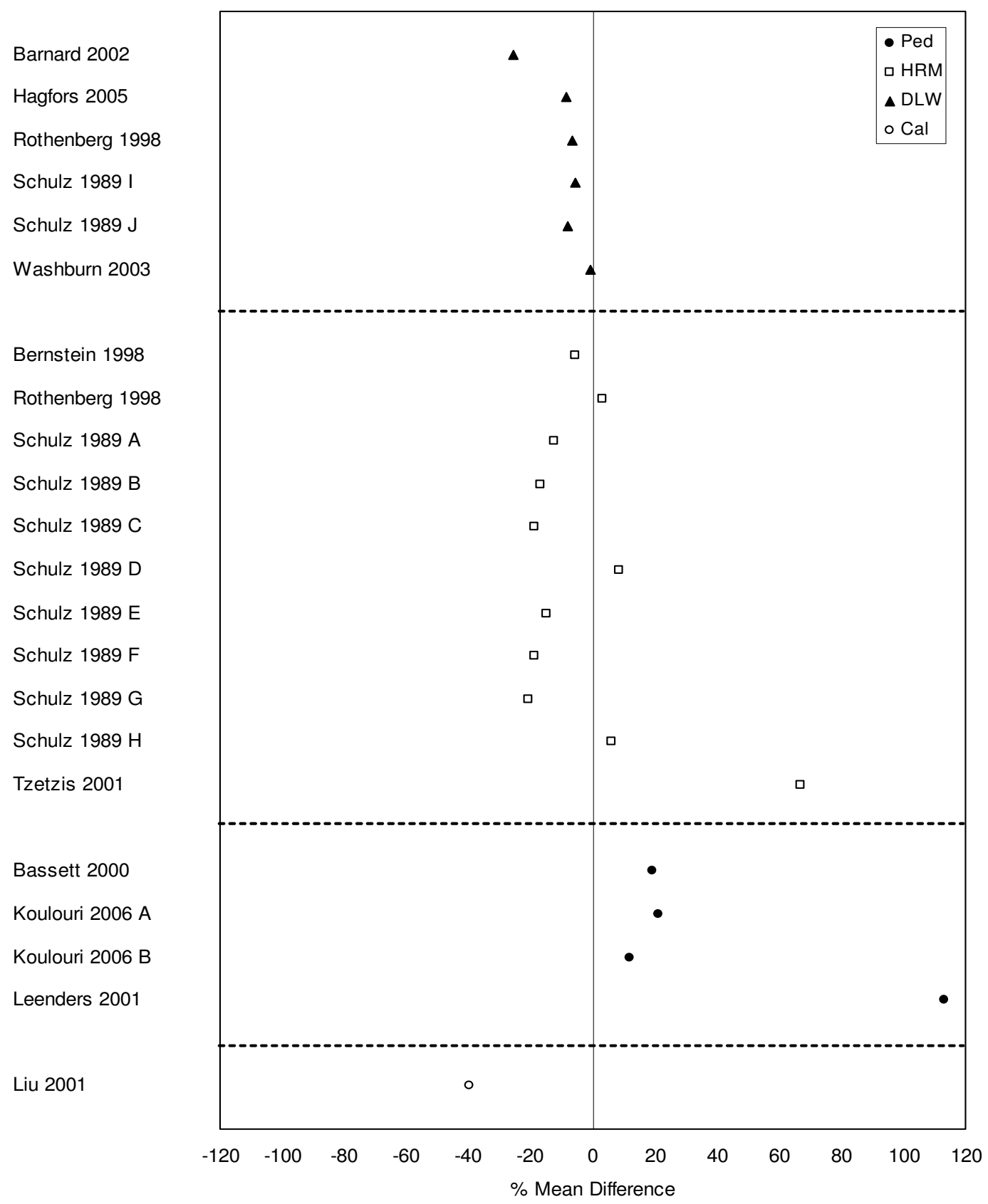

*Values $\geq 400 \%$ are not displayed

\section{Figure 6}

Forest plot of percent mean differences between doubly-labeled water, heart rate monitoring, pedometers, and indirect calorimetry and self-report measures from studies reporting combined results for males and females (excluding outliers $\geq \mathbf{4 0 0} \%$ ). Cal - calorimetry, DLW - doubly labeled water, HRM - heart rate monitor, Ped pedometer. 


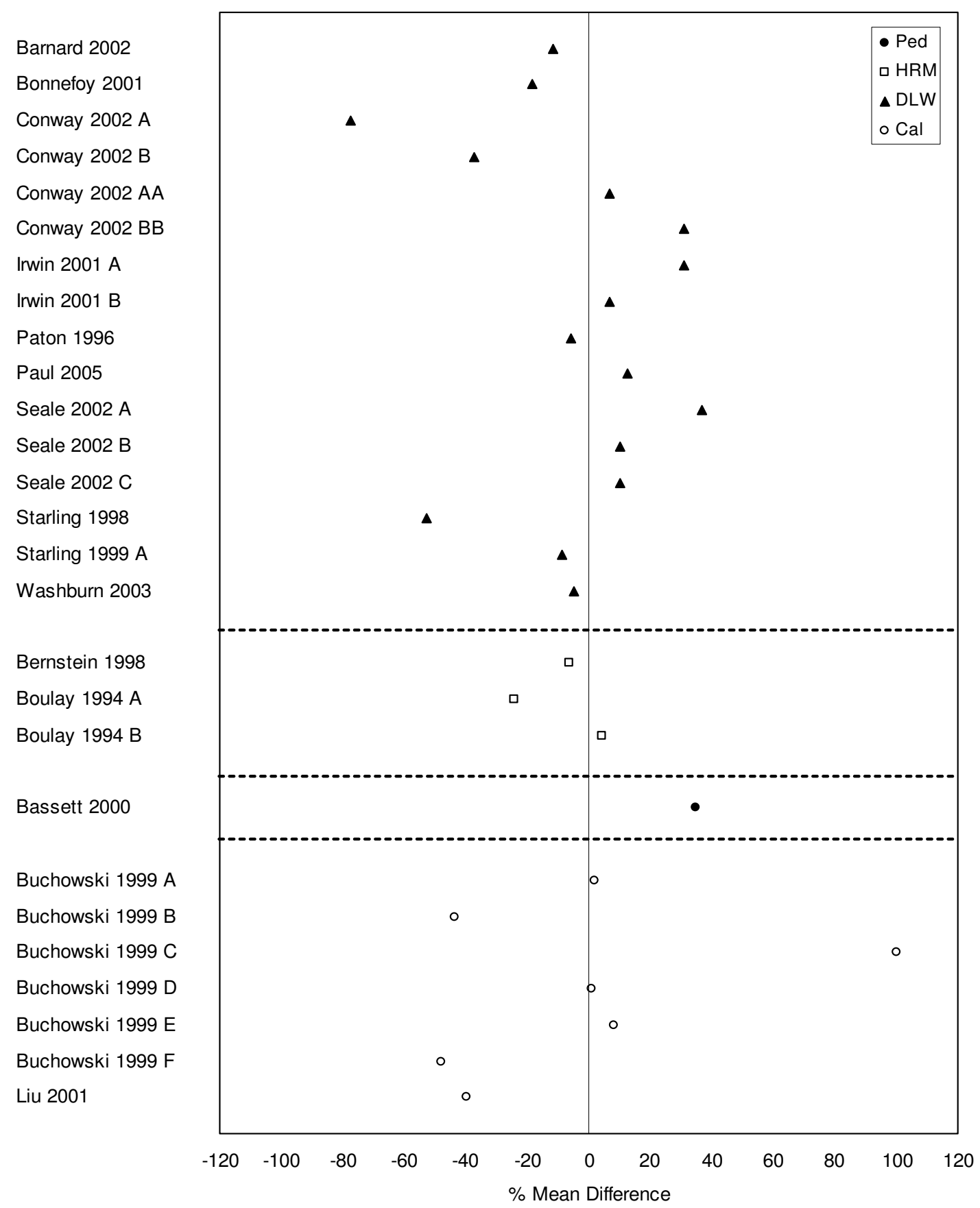

*Values $\geq 400 \%$ are not displayed

\section{Figure 7}

Forest plot of percent mean differences between doubly-labeled water, heart rate monitoring, pedometers, and indirect calorimetry and self-report measures from studies reporting results for males only (excluding outliers $\geq 400 \%$ ). Cal - calorimetry, DLW - doubly labeled water, HRM - heart rate monitor, Ped - pedometer. 


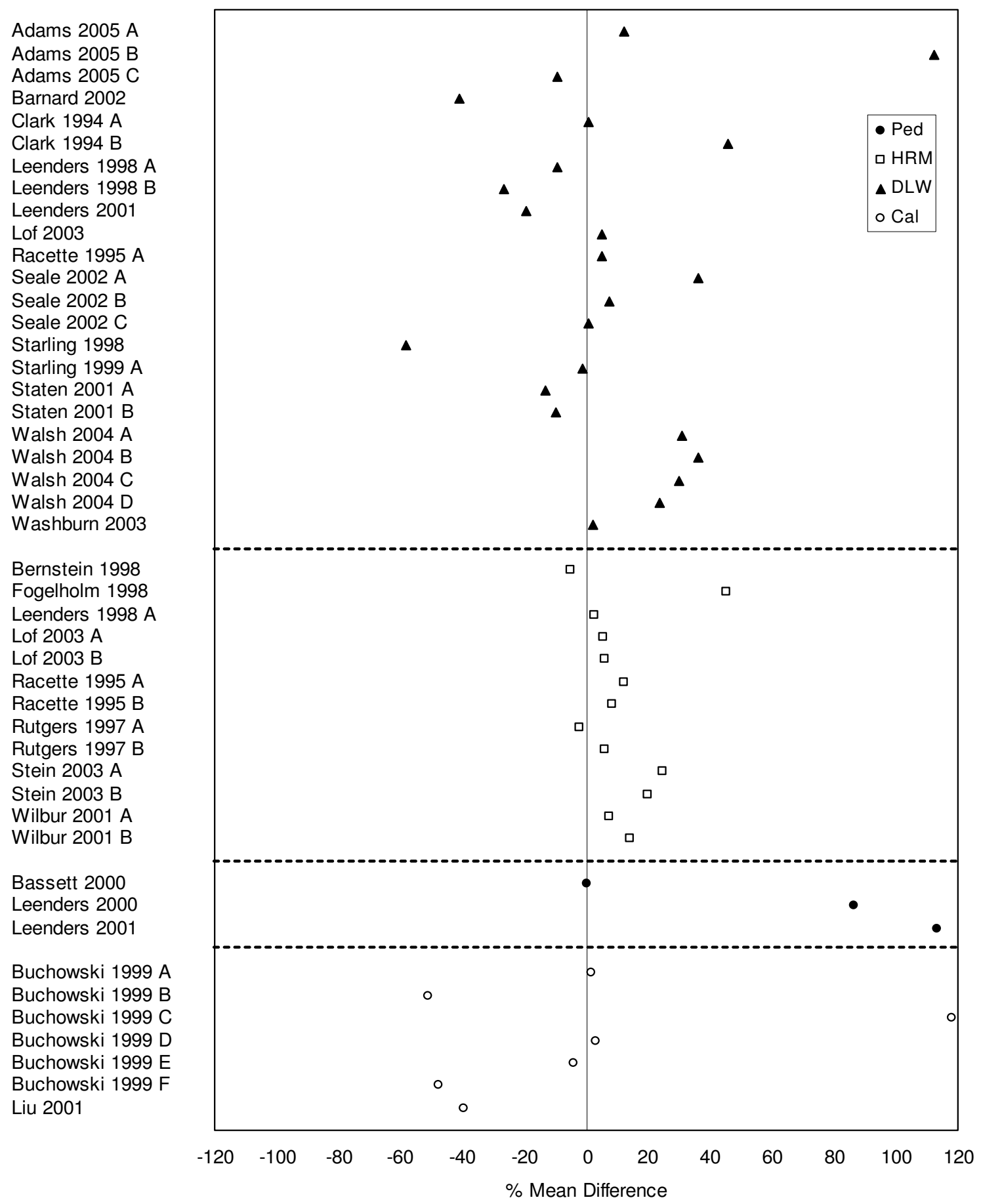

$*$ Values $\geq 400 \%$ are not displayed

\section{Figure 8}

Forest plot of percent mean differences between doubly-labeled water, heart rate monitoring, pedometers, and indirect calorimetry and self-report measures from studies reporting results for females only (excluding outliers $\geq \mathbf{4 0 0 \% )}$. Cal - calorimetry, DLW - doubly labeled water, HRM - heart rate monitor, Ped - pedometer. 
different time lags and periods of measurement. Few studies with comparable data reported exclusively on overweight/obese populations, but amongst those captured, the majority of studies reported higher levels of physical activity by self-report compared to the direct measures $[139,143,148,163-165,172]$. However, it was not possible to compare the overweight/obese percent mean differences to those reported in general populations.

Meta-analyses were not possible due to the substantial heterogeneity in units of reporting for physical activity measured by the various self-report and direct methods across the studies, and the significant lack of data with comparable units across measures. As a result, we were unable to determine the sensitivity of the values and the associated measures of error for the studies. Overall effect sizes to summarize the magnitude of discrepancy across the various measures of physical activity could therefore not be calculated.

\section{Discussion}

To the authors' knowledge this review represents the most comprehensive attempt to examine the relationship between self-report and directly measured estimates of adult physical activity in the international literature. Risk of bias was assessed and identified that just over one third of the studies had lower quality based on their description of the methods and external and internal validity. Overall, no clear trends emerged in the over- or underreporting of physical activity by self-report compared to direct methods. However, some results suggest that patterns in the agreement between self-report and direct measures of physical activity may exist, but they are likely to differ depending on the direct methods used for comparison and the sex of the population sampled. Interestingly, findings also identified that studies which categorized physical activity by level of exertion (e.g. light, moderate, vigorous) exhibited a trend wherein these categorized studies saw the mean percent differences between the selfreport and direct measures increasing with the higher category levels of intensity (i.e. vigorous physical activity). These larger differences may reflect a problem with selfreport measures attempting to capture higher levels of physical activity, or problems with participant interpretation and recall.

Many of the studies tested the relationship between selfreport and direct measures by using a correlation coefficient, but this is limited as correlation is only able to measure the strength of the relationship between two variables and cannot assess the level of agreement between them, as well as ignoring any bias in the data [191]. A more useful approach, the Bland-Altman method, provides a means for assessing the level of agreement between self-report and direct measures by deriving the mean dif- ference between the two measures and the limits of agreement. If the two measures possess good agreement and measure the same parameter of physical activity, then the cheaper and less invasive self-report methods may be valid substitutes for direct methods.

A meta-analysis would have allowed us to estimate the overall effect sizes for each of the direct measures and undertake a sensitivity analysis to further understand the degree of bias in the studies. Unfortunately, inconsistent methods and reporting among the studies included made such an analysis methodologically inappropriate. Further research in this area would benefit from greater consistency in the units of reporting and the methods used to facilitate comparisons. For instance, many studies did not report results using the same units, so estimates of agreement between the self-report and direct measures could not be computed. There was also an inconsistency in the number of days measured and the time lag between the self-report and direct measures. It is recommended that authors present their results using the same units for both measures (e.g. minutes/day, kcal/day), that the two measurements assess physical activity for and over the same time period, and that all relevant data including a mean and measurement of variance (i.e. standard deviation, standard error) be included in all reports.

Adhering to consistent reporting criteria would increase the comparability of results across studies and enable the calculation of overall effect sizes. At the population level, over- or underestimation of physical activity prevalence has important implications as these data are used to monitor physical activity trends, determine spending for research and physical activity interventions and programming, and to estimate physical inactivity-related risks of disease. Future studies may wish to refer to the updated Compendium of Physical Activities [192] which provides a coding scheme to classify physical activity by rate of energy expenditure. The Compendium offers a means to increase the comparability of results between self-report and direct measures, as well as across studies.

A lack of a clear trend amongst the differences between the self-report methods for assessing physical activity and the more robust direct methods is of concern, especially when trying to establish whether the measures could be used interchangeably. There are several possible explanations for the lack of a clear trend in the data. Many self-report instruments (such as the 7-day PAR) may not have the ability to account for activities of less than 10 minutes in duration or those with a level of exertion lower than brisk walking [193], whereas some of the direct methods (such as DLW) may capture all forms of physical movement. However, it is important to recognize that other direct measures such as accelerometers are unable to capture cer- 
tain types of activities such as swimming and activities involving the use of upper extremities. Our findings demonstrate the inherent difficulty self-report measures possess when trying to accurately capture data at various levels of exertion. Compared to direct measures, selfreport methods appear to estimate greater amounts of higher intensity (i.e. vigorous) physical activities than in the low-to-moderate levels.

Just as with some self-report measures not being able to capture all forms of activity, some direct measures may capture non-physical activity. For instance, the DLW technique is an accurate assessment of total energy expenditure, but it does not only capture physical activity, but rather all forms of energy expenditure including resting energy expenditure and the thermogenic effect of food. DLW is therefore expected to overestimate physical activity unless corrections are made. These and other measurement errors may inflate the between-individual variability in the energy expended in physical activity [194]. Finally, direct methods may be too sensitive to small errors derived from the various calibration methods employed and the equations used to define and categorize physical activity.

It is important to take into account all of these factors when comparing self-report and direct measures of physical activity. In specific circumstances (e.g. at different levels of activity) these two methods may not be comparable as they are not able to capture the same parameters of physical activity. Self-report measures may not able to accurately capture all levels of activity, but they may be able to capture how difficult an individual perceives an activity to be and the type of activity that is undertaken (e.g. leisure, work, transportation). Direct measures, on the other hand, may be more able to capture some of the information not captured in self-report methods (e.g. incidental daily movement and lower intensity activities), but also possess their own limitations such as the inability to capture arm movements and various types of physical activity (e.g. swimming).

Concern regarding the discrepancy between self-reported and directly measured physical activity were recently reported by Troiano and colleagues who examined data from the 2003-2004 National Health and Nutrition Examination Survey (NHANES) which contained the first direct measurements of physical activity in a nationally representative U.S. sample [195]. They compared selfreported adherence estimates of physical activity recommendations with those directly measured by accelerometer. Their findings identified that self-reported adherence estimates were much higher than those measured by accelerometer. The authors hypothesize that the overestimation may be a result of respondents misclassifying sed- entary or light activity as moderate or from underestimations of activity duration by the accelerometers.

Other factors, such as those related to the population under study, may influence the ability of self-report and direct methods to capture the same measurement. For example, our findings show that in studies with a focus on overweight/obese individuals, self-reported physical activity was overestimated in all cases except for DLW studies involving combined male/female and male-only data. Our results differed from those reported by Irwin, Ainsworth and Conway (2001) [58]. Their study consisted of 24 males and used DLW to compare energy expenditure estimates with those obtained by physical activity record and the 7-day PAR. The investigators observed an overestimation of energy expenditure in participants with higher body fat using the physical activity record, but not the 7-day PAR. A comparison of the same sample by body mass index (BMI) identified that those with a $\mathrm{BMI} \geq 25 \mathrm{~kg} / \mathrm{m}^{2}$ overestimated energy expenditure from physical activity records and the 7-day PAR. In confirmation of the trends within our accelerometer data, a recent study (published after our search) of 154 subjects compared a physical activity questionnaire to accelerometry data and identified that the accuracy of the physical activity questionnaire was higher for males than females and for those with a lower BMI [196]. It is likely that a response bias exists due to social desirability, and influences the degree of over-reporting of physical activity by overweight/obese individuals. Future research and synthesis is needed to identify whether a bias does in fact exist and if so, whether it differs by gender, and to what extent.

This review had limitations that should be considered when examining the results. First, the sample was limited to studies that included directly comparable data between self-report and direct measures (same units for both measures) or a comparison by way of correlation. Access to primary data from each study was not feasible; therefore, we relied upon reported comparisons and the means of measured physical activity. This reduced the number of studies with reported measures of physical activity by selfreport and direct methods and limited our ability to accurately assess the degree of agreement between the two measures. However, when possible we converted noncomparable units to increase the number of studies used. The review did not assess the agreement between proxyreported physical activity and direct measures. Proxyreport data are less prevalent but is an important means for assessing physical activity in sub-populations such as those who are chronically ill, disabled, or elderly, and who are unable to self-report on their own physical activity levels. Further research is required to assess the validity of proxy-report measures of physical activity when com- 
pared to direct methods. Finally, this review did not discern between differences in study protocols related to calibration, cut-points, or collection of the measurements and other population specific characteristics.

\section{Conclusion}

In conclusion, this review provides an objective summary of the difference in physical activity levels assessed via selfreport methods compared to directly measured physical activity. The results may assist researchers considering the use of self-report or direct measurement methods and serves as a note of caution that self-report and directly measured physical activity can differ greatly. Overall there were no clear trends in the degree to which physical activity measured by self-report and direct measures differ. The strength of trends differed by the direct method employed and by the gender of the population sampled. One-third of the studies were of poor quality with most studies having failed to report actual probabilities or measures of variability for estimates and the representativeness of their samples. The costs and benefits of direct measurement need to be considered in any study in order to determine if the added resources required for personnel training and laboratory analyses justify the possible increase in the precision of results. At this time, it is not possible to draw any definitive conclusions concerning the validity of selfreport measurements compared to various direct methods, but caution should be exerted when comparing studies across methods.

\section{Competing interests}

The authors declare that they have no competing interests.

\section{Authors' contributions}

SAP carried out the design, bibliographic search, article screening, data abstraction and synthesis and drafted and edited the manuscript. KBA participated in its design and coordination and helped edit the manuscript. MH participated in article screening, data abstraction and editing of the manuscript. JH participated in data abstraction, data synthesis and helped edit the manuscript. SCG participated in the design of the study, provided methodological input, and assisted in the editing of the manuscript. MT conceived the study, and participated in its design and coordination and helped to draft the manuscript. All authors read and approved the final manuscript.

\section{Acknowledgements}

The authors would like to thank David Moher for insightful guidance in the development of the research methods and Margaret Sampson for her technical assistance with the search strategy. The first author acknowledges financial support from Statistics Canada for the preparation of the paper.

\section{References}

I. Caspersen CJ, Powell EC, Christenson GM: Physical activity, exercise, and physical fitness: definitions and distinctions for health-related research. Public Health 1985, 100:|26-|3|.
2. Katzmarzyk PT, Gledhill N, Shephard RJ: The economic burden of physical inactivity in Canada. CMAJ 2000, 163:1435-1440.

3. Dishman RK, Washburn RA, Schoeller DA: Measurement of physical activity. QUEST 200I, 53:295-309.

4. Shephard RJ: Limits to the measurement of habitual physical activity by questionnaires. BrJ Sports Med 2003, 37:197-206.

5. Ainslie PN, Reilly T, Westerterp KR: Estimating human energy expenditure: a review of techniques with particular references to doubly labelled water 38. Sports Med 2003, 33:683-698.

6. Adamo KB, Prince SA, Tricco AC, Connor Gorber S, Tremblay M: A comparison of direct versus self-report measures for assessing physical activity in the pediatric population: a systematic review. Int J Pediatr Obes in press.

7. Downs SH, Black N: The feasibility of creating a checklist for the assessment of the methodological quality of both randomised and non-randomised studies of health care intervention. J Epidemiol Community Health 1998, 52:377-384.

8. Saunders DL, Soomro GM, Buckingham J, Jamtvedt G, Raina P: Assessing the methodological quality of nonrandomized intervention studies. Western J Nurs Res 2003, 25:223-237.

9. Deeks JJ, Dinnes JD, D'Amico R, Sowden AJ, Sakarovitch C, Song F, Petticrew M, Altman DG: Evaluating non-randomised intervention studies. Health Technol Assess 2003, 7(27): I-I 73.

10. Aadahl M, Jorgensen T: Validation of a new self-report instrument for measuring physical activity. Med Sci Sports Exer 2003, 35:1196-1202.

1I. Adams SA: Methodological and substantive issues: The relationship between physical activity and breast cancer. In PhD Thesis University of South Carolina; 2003.

12. Adams SA, Matthews CE, Ebbeling CB, Moore CG, Cunningham JE, Fulton J, Hebert JR: The effect of social desirability and social approval on self-reports of physical activity. Am J Epidemiol 2005, 161:389-398.

13. Ainsworth BE, Richardson MT, Jacobs DR Jr, Leon AS, Sternfeld B: Accuracy of recall of occupational physical activity by questionnaire. J Clin Epidemiol 1999, 52:219-227.

14. Ainsworth BE, Bassett DR Jr, Strath SJ, Swartz AM, O'Brien WL, Thompson RW, Jones DA, Macera CA, Kimsey CD: Comparison of three methods for measuring the time spent in physical activity. Med Sci Sports Exer 2000, 32:S457-S464.

15. Ainsworth BE, Sternfeld B, Richardson MT, Jackson K: Evaluation of the kaiser physical activity survey in women. Med Sci Sports Exer 2000, 32: 1327-1338.

16. Armstrong CA: The stages of change in exercise adoption and adherence: Evaluation of measures with self-report and objective data. In PhD Thesis University of California, San Diego and San Diego State University; 1998.

17. Atienza AA, King AC: Comparing self-reported versus objectively measured physical activity behavior: a preliminary investigation of older Filipino American women. Res $Q$ Exerc Sport 2005, 76(3):358-362.

18. Bassett DR, Schneider PL, Huntington GE: Physical activity in an Old Order Amish community. Med Sci Sports Exer 2004, 36:79-85

19. Bassett DR Jr, Cureton AL, Ainsworth BE: Measurement of daily walking distance-questionnaire versus pedometer. Med Sci Sports Exer 2000, 32:1018-1023.

20. Bernstein M, Sloutskis D, Kumanyika S, Sparti A, Schutz Y, Morabia A: Data-based approach for developing a physical activity frequency questionnaire. Am J Epidemiol 1998, I 47: 147-I54.

21. Bisgaard T, Kjaersgaard M, Bernhard A, Kehlet H, Rosenberg j: Computerized monitoring of physical activity and sleep in postoperative abdominal surgery patients. J Clin Monitor Comp 1999, 15:1-8.

22. Bjorgaas M, Vik JT, Saeterhaug A, Langlo L, Sakshaug T, Mohus RM, Grill V: Relationship between pedometer-registered activity, aerobic capacity and self-reported activity and fitness in patients with type 2 diabetes. Diabetes Obes Metab 2005, 7:737-744.

23. Bonnefoy M, Normand S, Pachiaudi C, Lacour JR, Laville M, Kostka T: Simultaneous validation of ten physical activity questionnaires in older men: a doubly labeled water study. J Am Geriatr Soc 200I, 49:28-35.

24. Brach JS: The relation of physical activity to functional status over a seventeen-year time period in community-dwelling older women. In PhD Thesis University of Pittsburgh; 2000. 
25. Brown WJ, Ringuet C, Trost SG: How active are young adult women? Health Promot J Aust 2002:23-28.

26. Bulley C, Donaghy M, Payne A, Mutrie N: Validation and modification of the Scottish Physical Activity Questionnaire for use in a female student population. Int J Health Promot Edu 2005, 43:

27. Carter-Nolan PL, Adams-Campbell LL, Makambi K, Lewis S, Palmer JR, Rosenberg L: Validation of Physical Activity Instruments: Black Women's Health Study. Ethn Dis 2006, I6(4):943-947.

28. Cauley JA, Kriska AM, LaPorte RE, Sandler RB, Pambianco G: A two year randomized exercise trial in older women: effects on HDL-cholesterol. Atherosclerosis 1987, 66:247-258.

29. Chasan-Taber L, Schmidt MD, Roberts DE, Hosmer D, Markenson G, Freedson PS: Development and validation of a Pregnancy Physical Activity Questionnaire. Med Sci Sports Exer 2004, 36:1750-1760

30. Chen $\mathrm{AH}-\mathrm{W}$ : The effectiveness of a home-based intervention to promote walking in ethnic minority women. In PhD Thesis University of California, San Diego and San Diego State University; 1995.

31. Conn VS, Minor MA, Mehr DR, Burks KJ: Recording activity in older women with TriTrac. Am J Health Behav 2000, 24:370-378.

32. Conway JM, Irwin ML, Ainsworth BE: Estimating energy expenditure from the Minnesota Leisure Time Physical Activity and Tecumseh Occupational Activity questionnaires - a doubly labeled water validation. J Clin Epidemiol 2002, 55:392-399.

33. Conway JM, Seale JL, Jacobs DR Jr, Irwin ML, Ainsworth BE: Comparison of energy expenditure estimates from doubly labeled water, a physical activity questionnaire, and physical activity records. Am / Clin Nutr 2002, 75:5 I9-525.

34. Cook TC: Epidemiology of fitness in the elderly: a twin approach. In PhD Thesis University of Pittsburgh; 1986.

35. Craig CL, Marshall AL, Sjostrom M, Bauman AE, Booth ML, Ainsworth BE, Pratt M, Ekelund U, Yngve A, Sallis JF, et al:: Internationa physical activity questionnaire: I2-country reliability and validity. Med Sci Sports Exer 2003, 35: I38I-1395.

36. Davies SW, Jordan SL, Lipkin DP: Use of limb movement sensors as indicators of the level of everyday physical activity in chronic congestive heart failure. Am J Cardiol 1992, 69(19): $1581-1586$.

37. De Abajo S, Larriba R, Marquez S: Validity and reliability of the Yale Physical Activity Survey in Spanish elderly. J Sports Med Phys Fitness 200I, 4 I (4):479-485.

38. del Aguila MA: Assessment of physical activity in patients with diabetes. In PhD Thesis University of Washington; 1998

39. Dinger MK: Reliability and convergent validity of the National College Health Risk Behavior Survey Physical Activity items. Am J Health Educ 2003, 34:162-166.

40. Dinger MK, Oman RF, Taylor EL, Vesely SK, Able J: Stability and convergent validity of the Physical Activity Scale for the Elderly (PASE). I Sports Med Phys Fitness 2004, 44(2): 186-192.

41. Dishman RK, Darracott CR, Lambert LT: Failure to generalize determinants of self-reported physical activity to a motion sensor. Med Sci Sports Exerc 1992, 24(8):904-910.

42. Dubbert PM, Weg MW Vander, Kirchner KA, Shaw B: Evaluation of the 7-day physical activity recall in urban and rural men. Med Sci Sports Exerc 2004, 36(9): 1646-1654.

43. Dubbert PM, White JD, Grothe KB, O'Jile J, Kirchner KA: Physical activity in patients who are severely mentally ill: feasibility of assessment for clinical and research applications. Arch Psychiatr Nurs 2006, 20:205-209.

44. Ekelund U, Sepp H, Brage S, Becker W, Jakes R, Hennings M, Wareham NJ: Criterion-related validity of the last 7-day, short form of the International Physical Activity Questionnaire in Swedish adults. Public Health Nutr 2006, 9:258-265.

45. Elmore BG: An evaluation of five physical activity assessment methods in a group of women. In PhD Thesis University of Illinois at Urbana-Champaign; 1989.

46. Evangelista LS, Dracup K, Doering L, Moser DK, Kobashigawa J: Physical activity patterns in heart transplant women. J Cardiovasc Nurs 2005, 20:334-339.

47. Faulkner G, Cohn T, Remington G: Validation of a physical activity assessment tool for individuals with schizophrenia. Schizophr Res 2006, 82:225-23I.

48. Friedenreich CM, Courneya KS, Neilson HK, Matthews CE, Willis G, Irwin M, Troiano R, Ballard-Barbash R: Reliability and validity of the Past Year Total Physical Activity Questionnaire. Am J Epidemiol 2006, 163:959-970.

49. Fu LL: Health status, functional state and physical activity level in community dwelling elderly women. In PhD Thesis University of Pittsburgh; 1995.

50. Gardner AW, Montgomery PS: The Baltimore activity scale for intermittent claudication: a validation study. Vascular \& Endovascular Surgery 2006, 40:383-391.

51. Ginis KA, Latimer AE, Hicks AL, Craven BC: Development and evaluation of an activity measure for people with spinal cord injury. Med Sci Sports Exer 2005, 37: I099-IIII

52. Gretler DD, Carlson GF, Montano AV, Murphy MB: Diurnal blood pressure variability and physical activity measured electronically and by diary. Am J Hypertens 1993, 6:127-133.

53. Hagfors L, Westerterp K, Skoldstam L, Johansson G: Validity of reported energy expenditure and reported intake of energy, protein, sodium and potassium in rheumatoid arthritis patients in a dietary intervention study. Eur J Clin Nutr 2005, 59:238-245

54. Hagstromer M, Oja P, Sjostrom M: The International Physical Activity Questionnaire (IPAQ): a study of concurrent and construct validity. Public Health Nutr 2006, 9:755-762.

55. Harada ND, Chiu V, King AC, Stewart AL: An evaluation of three self-report physical activity instruments for older adults. Med Sci Sports Exer 200I, 33:962-970.

56. Hayden-Wade HA, Coleman KJ, Sallis JF, Armstrong C: Validation of the telephone and in-person interview versions of the 7 day PAR. Med Sci Sports Exer 2003, 35:80I-809.

57. Iqbal R, Rafique G, Badruddin S, Qureshi R, Gray-Donald K: Validating MOSPA questionnaire for measuring physical activity in Pakistani women. Nutr J 2006, 5: I8.

58. Irwin ML, Ainsworth BE, Conway JM: Estimation of energy expenditure from physical activity measures: determinants of accuracy. Obes Res 200I, 9:5 17-525.

59. Jacobs DR Jr, Ainsworth BE, Hartman TJ, Leon AS: A simultaneous evaluation of 10 commonly used physical activity questionnaires. Med Sci Sports Exer 1993, 25:8I-91.

60. Jakes RW, Day NE, Luben R, Welch A, Bingham S, Mitchell J, Hennings $\mathrm{S}$, Rennie K, Wareham NJ: Adjusting for energy intake - what measure to use in nutritional epidemiological studies? Int J Epidemiol 2004, 33: 1382-1 386.

6I. Jansen L: The effect of exercise on explanatory style in HIVinfected men. In PhD Thesis United States International University; 2002.

62. Johansen KL, Chertow GM, Ng AV, Mulligan K, Carey S, Schoenfeld PY, Kent-Braun JA: Physical activity levels in patients on hemodialysis and healthy sedentary controls. Kidney International 2000, 57:2564-2570.

63. Johansen KL, Painter P, Kent-Braun JA, Ng AV, Carey S, Da SM, Chertow GM: Validation of questionnaires to estimate physical activity and functioning in end-stage renal disease. Kidney International 200I, 59:.

64. Johnson-Kozlow MF: Validity and measurement bias in three self-report measures of physical activity among women diagnosed with breast cancer. In PhD Thesis University of California, San Diego; 2003.

65. Johnson-Kozlow M, Rock CL, Gilpin EA, Hollenbach KA, Pierce JP: Validation of the WHI brief physical activity questionnaire among women diagnosed with breast cancer. Am J Health Behav 2007, 31 : 193-202.

66. King WC, Brach JS, Belle S, Killingsworth R, Fenton M, Kriska AM The relationship between convenience of destinations and walking levels in older women. Am J Health Promot 2003, 18:74-82.

67. Kolbe-Alexander TL, Lambert EV, Harkins JB, Ekelund U: Comparison of two methods of measuring physical activity in South African older adults. J Aging Phys Act 2006, I4(I):98-II4.

68. Krishnamoorthy JS: The transmission of physical activity and related cognitions among African-American adolescent females and their primary female caregiver. Dissertation Abstracts International: Section B: The Sciences and Engineering 2002, 63:

69. Kriska AM: Assessment of current and historical physical activity in the Pima Indians. In PhD Thesis University of Pittsburgh; 1988.

70. Kriska AM, Knowler WC, LaPorte RE, Drash AL, Wing RR, Blair SN, Bennett PH, Kuller LH: Development of questionnaire to exam- 
ine relationship of physical activity and diabetes in Pima Indians. Diabetes Care 1990, I3:40 I-4I I.

71. Lambert P: Physical activity and the oldest-old: A comparison of self-report and accelerometer readings. In PhD Thesis University of Manitoba (Canada); 2006.

72. LaPorte RE, Black-Sandler R, Cauley JA, Link M, Bayles C, Marks B: The assessment of physical activity in older women: analysis of the interrelationship and reliability of activity monitoring activity surveys, and caloric intake. J Gerontol 1983, 38:394-397.

73. Lasuzzo J: Ability of the California State University, Fullerton Physical Activity Questionnaire to assess physical activity in older individuals. In PhD Thesis The University of Alabama; 2004.

74. Leenders NYJM: Evaluation of methods to assess physical activity. In PhD Thesis The Ohio State University; 1998.

75. Leenders NYJM, Sherman WM, Nagaraja HN: Comparisons of four methods of estimating physical activity in adult women. Med Sci Sports Exer 2000, 32:1320-1326.

76. Leenders NY, Sherman WM, Nagaraja HN, Kien CL: Evaluation of methods to assess physical activity in free-living conditions. Med Sci Sports Exerc 200I, 33(7): I233-1240.

77. Lemmer JT, Ivey FM, Ryan AS, Martel GF, Hurlbut DE, Metter JE, Fozard JL, Fleg JL, Hurley BF: Effect of strength training on resting metabolic rate and physical activity: age and gender comparisons. Med Sci Sports Exerc 200I, 33:532-54I.

78. Lewis JM: A phenomenological analysis of the physical activity experiences of youth and their parents. In PhD Thesis Dalhousie University (Canada); 2005.

79. Lindseth G, Vari P: Measuring physical activity during pregnancy. West J Nurs Res 2005, 27:722-734.

80. Lof M, Hannestad U, Forsum E: Comparison of commonly used procedures, including the doubly-labelled water technique, in the estimation of total energy expenditure of women with special reference to the significance of body fatness. Br J Nutr 2003, 90:961-968.

81. Lowther M, Mutrie N, Loughlan C, McFarlane C: Development of a Scottish physical activity questionnaire: a tool for use in physical activity interventions. Br J Sports Med 1999, 33:244-249.

82. Macfarlane DJ, Lee CC, Ho EY, Chan KL, Chan D: Convergent validity of six methods to assess physical activity in daily life. J Appl Physiol 2006, I0I:I328-1334.

83. Mader U, Martin BW, Schutz Y, Marti B: Validity of four short physical activity questionnaires in middle-aged persons. Med Sci Sports Exer 2006, 38: I255-1266.

84. Mahabir S, Baer DJ, Giffen C, Clevidence BA, Campbell WS, Taylor $P R$, Hartman TJ: Comparison of energy expenditure estimates from 4 physical activity questionnaires with doubly labeled water estimates in postmenopausal women. Am J Clin Nutr 2006, 84:230-236.

85. Martinez-Gonzalez MA, Lopez-Fontana C, Varo JJ, Sanchez-Villegas A, Martinez JA: Validation of the Spanish version of the physical activity questionnaire used in the Nurses' Health Study and the Health Professionals' Follow-up Study. Public Health Nutr 2005, 8:920-927.

86. Masse LC, Fulton JE, Watson KL, Mahar MT, Meyers MC, Wong WW: Influence of body composition on physical activity validation studies using doubly labeled water. I Appl Physiol 2004, 96:1357-1364

87. Masse LC, Eason KE, Tortolero SR, Kelder SH: Comparing participants' rating and compendium coding to estimate physical activity intensities. Meas Phys Edu Exer Sci 2005, 9:.

88. Matthews CE, Freedson PS: Field trial of a three-dimensional activity monitor: comparison with self report. Med Sci Sports Exer 1995, 27:107/-1078.

89. Matthews CE, Freedson PS, Hebert JR, Stanek EJ III, Merriam PA, Ockene IS: Comparing physical activity assessment methods in the Seasonal Variation of Blood Cholesterol Study. Med Sci Sports Exerc 2000, 32:976-984.

90. Matthews CE, Ainsworth BE, Hanby C, Pate RR, Addy C, Freedson PS, Jones DA, Macera CA: Development and testing of a short physical activity recall questionnaire. Med Sci Sports Exerc 2005, 37:986-994.

91. Matthews CE, Wilcox S, Hanby CL, Der AC, Heiney SP, Gebretsadik T, Shintani A: Evaluation of a I 2-week home-based walking intervention for breast cancer survivors. Support Care Cancer 2007, | 5:203-211.
92. McDermott MM, Liu K, O'Brien E, Guralnik JM, Criqui MH, Martin G], Greenland $\mathrm{P}$ : Measuring physical activity in peripheral arterial disease: a comparison of two physical activity questionnaires with an accelerometer. Angiology 2000, $51: 91-100$

93. Mckeen NA: The meaning of motor activity: Emotion, temperament, mood, and laterality. Dissertation Abstracts International: Section B: The Sciences and Engineering 200I, 6I:

94. Meriwether RA, McMahon PM, Islam N, Steinmann WC: Physical activity assessment: validation of a clinical assessment tool. Am J Prev Med 2006, 3 I:484-49I.

95. Miller DJ, Freedson PS, Kline GM: Comparison of activity levels using the Caltrac accelerometer and five questionnaires. Med Sci Sports Exerc 1994, 26:376-382.

96. Motl RW, McAuley E, Snook EM, Scott JA: Validity of physical activity measures in ambulatory individuals with multiple sclerosis. Disability \& Rehabilitation 2006, 28: I I5I-I I56.

97. $\mathrm{Ng} \mathrm{AV}$, Kent-Braun JA: Quantitation of lower physical activity in persons with multiple sclerosis. Med Sci Sports Exerc 1997, 29:517-523.

98. Otis RB, Brown AS, Womack C], Fonong T, Gardner AW: Relationship between physical activity recall and free-living daily physical activity in older claudicants. Angiology 2000, 5I:18I-188.

99. Owens JF: Physical activity and cardiovascular risk factors: A cross-sectional study of premenopausal women. In PhD Thesis University of Pittsburgh; 1989.

100. Paton NI, Elia M, Jebb SA, Jennings G, Macallan DC, Griffin GE: Total energy expenditure and physical activity measured with the bicarbonate-urea method in patients with human immunodeficiency virus infection. Clin Sci 1996, 91:241-245.

101. Patterson SM, Krantz DS, Montgomery LC, Deuster PA, Hedges SM, Nebel LE: Automated physical activity monitoring: validation and comparison with physiological and self-report measures. Psychophysiology 1993, 30:296-305.

102. Paul DR, Rhodes DG, Kramer M, Baer DJ, Rumpler WV: Validation of a food frequency questionnaire by direct measurement of habitual ad libitum food intake. Am J Epidemiol 2005, 162:806-8I4.

103. Philippaerts RM, Westerterp KR, Lefevre J: Doubly labelled water validation of three physical activity questionnaires. Int $J$ Ssports Med 1999, 20:284-289.

104. Philippaerts RM, Westerterp KR, Lefevre J: Comparison of two questionnaires with a tri-axial accelerometer to assess physical activity patterns. Int J Sports Med 200I, 22:34-39.

105. Pitta F, Troosters T, Spruit MA, Decramer M, Gosselink R: Activity monitoring for assessment of physical activities in daily life in patients with chronic obstructive pulmonary disease. Arch Phys Med Rehabil 2005, 86: 1979-1985.

106. Pols MA, Peeters PH, Kemper HC, Collette HJ: Repeatability and relative validity of two physical activity questionnaires in elderly women. Med Sci Sports Exerc 1996, 28:1020-1025.

107. Pongurgsorn C: A questionnaire for assessment of physical activity in Thailand. In PhD Thesis University of Illinois at UrbanaChampaign; 2002.

108. Poudevigne MS, O'Connor PJ: Physical activity and mood during pregnancy. Med Sci Sports Exerc 2005, 37:

109. Rauh MJ, Hovell MF, Hofstetter CR, Sallis JF, Gleghorn A: Reliability and validity of self-reported physical activity in Latinos. Int $J$ Epidemiol 1992, 21:966-971.

110. Reis JP, Dubose KD, Ainsworth BE, Macera CA, Yore MM: Reliability and validity of the occupational physical activity questionnaire. Med Sci Sports Exerc 2005, 37:2075-2083.

III. Richardson MT, Leon AS, Jacobs DR Jr, Ainsworth BE, Serfass R: Comprehensive evaluation of the Minnesota Leisure Time Physical Activity Questionnaire. J Clin Epidemiol 1994, 47:27I-28I

112. Richardson MT, Ainsworth BE, Wu HC, Jacobs DR Jr, Leon AS: Ability of the Atherosclerosis Risk in Communities (ARIC)/Baecke Questionnaire to assess leisure-time physical activity. Int J Epidemiol 1995, 24:685-693.

113. Richardson MT, Ainsworth BE, Jacobs DR, Leon AS: Validation of the Stanford 7-day recall to assess habitual physical activity. Ann Epidemiol 200I, II:145-153.

114. Rothenberg E, Bosaeus I, Lernfelt B, Landahl S, Steen B: Energy intake and expenditure: validation of a diet history by heart 
rate monitoring, activity diary and doubly labeled water. Eur J Clin Nutr 1998, 52:832-838.

115. Rousham EK, Clarke PE, Gross H: Significant changes in physical activity among pregnant women in the UK as assessed by accelerometry and self-reported activity. Eur J Clin Nutr 2006, 60:393-400.

1 16. Rutgers CJ, Klijn MJ, Deurenberg P: The assessment of 24-hour energy expenditure in elderly women by minute-by-minute heart rate monitoring. Ann Nutr Metab 1997, 41:83-88.

1 17. Rutter S: Estimates of energy expenditure in women and a biofeedback device for weight loss. In PhD Thesis University of New Hampshire; 1990.

1 18. Saleh KJ, Mulhall KJ, Bershadsky B, Ghomrawi HM, White LE, Buyea CM, Krackow KA: Development and validation of a lowerextremity activity scale. Use for patients treated with revision total knee arthroplasty. I Bone Joint Surg Am 2005, 87:1985-1994.

119. Schmidt MD, Freedson PS, Chasan-Taber L: Estimating physical activity using the CSA accelerometer and a physical activity log. Med Sci Sports Exer 2003, 35: I605-I6II.

120. Schmidt MD, Freedson PS, Pekow P, Roberts D, Sternfeld B, ChasanTaber L: Validation of the Kaiser Physical Activity Survey in pregnant women. Med Sci Sports Exer 2006, 38:42-50.

121. Schulz S, Westerterp KR, Bruck K: Comparison of energy expenditure by the doubly labeled water technique with energy intake, heart rate, and activity recording in man. Am J Clin Nutr 1989, 49: I I46-I I54.

122. Schulz LO, Harper IT, Smith C], Kriska AM, Ravussin E: Energy intake and physical activity in Pima Indians: comparison with energy expenditure measured by doubly-labeled water. Obes Res 1994, 2:54I-548.

123. Sieminski DJ, Cowell LL, Montgomery PS, Pillai SB, Gardner AW: Physical activity monitoring in patients with peripheral arterial occlusive disease. / Cardiopulm rehabil 1997, 17:43-47.

124. Sims J, Smith F, Duffy A, Hilton S, Sims J, Smith F, Duffy A, Hilton S: The vagaries of self-reports of physical activity: a problem revisited and addressed in a study of exercise promotion in the over 65s in general practice. Family Practice 1999, 16:152-157.

125. Singh PN, Fraser GE, Knutsen SF, Lindsted KD, Bennett HW: Validity of a physical activity questionnaire among African-American Seventh-day Adventists. Med Sci Sports Exer 200I, 33:468-475

126. Sirard JR, Melanson EL, Li L, Freedson PS: Field evaluation of the Computer Science and Applications, Inc. physical activity monitor. Med Sci Sports Exerc 2000, 32:695-700.

127. Smith BJ, Marshall AL, Huang N: Screening for physical activity in family practice: evaluation of two brief assessment tools. Am J Prev Med 2005, 29:256-264.

128. Sobngwi E, Mbanya JC, Unwin NC, Aspray TJ, Alberti KG: Development and validation of a questionnaire for the assessment of physical activity in epidemiological studies in Sub-Saharan Africa. Int J Epidemiol 2001, 30:136|-1368.

129. Speck BJ, Looney SW: Self-reported physical activity validated by pedometer: a pilot study. Public Health Nurs 2006, 23:88-94.

130. Stanish HI, Draheim CC: Assessment of walking activity using a pedometer and survey in adults with mental retardation. Adapt Phys Activity $Q 2005,22: 136-145$.

I3I. Starling RD, Toth MJ, Matthews DE, Poehlman ET: Energy requirements and physical activity of older free-living AfricanAmericans: a doubly labeled water study. J Clin Endocr Metab 1998, 83:1529-1534.

132. Steele R, Mummery K: Occupational physical activity across occupational categories. I Sci Med Sport 2003, 6:398-407.

133. Stel VS, Smit JH, Pluijm SM, Visser M, Deeg DJ, Lips P: Comparison of the LASA Physical Activity Questionnaire with a 7-day diary and pedometer. I Clin Epidemiol 2004, 57:252-258.

134. Strath SJ, Bassett DR Jr, Ham SA, Swartz AM: Assessment of physical activity by telephone interview versus objective monitoring. Med Sci Sports Exerc 2003, 35:2 I I2-2 I I8.

135. Strath SJ, Bassett DR Jr, Swartz AM: Comparison of the college alumnus questionnaire physical activity index with objective monitoring. Ann Epidemiol 2004, 14:409-4I 5.

136. Strycker LA, Duncan SC, Chaumeton NR, Duncan TE, Toobert DJ: Reliability of pedometer data in samples of youth and older women. Int J Behav Nutr Phys Act 2007, 4:4.
137. Sugimoto A, Hara Y, Findley TW, Yoncmoto K: A useful method for measuring daily physical activity by a three-direction monitor. Scand J Rehabil Med 1997, 29:37-42.

138. Taylor CB, Coffey T, Berra K, laffaldano R, Casey K, Haskell WL: Seven-day activity and self-report compared to a direct measure of physical activity. Am J Epidemiol 1984, 120:8 18-824.

139. Timperio A, Salmon J, Crawford D: Validity and reliability of a physical activity recall instrument among overweight and non-overweight men and women. I Sci Med Sport 2003, 6:477-491.

140. Timperio A, Salmon J, Rosenberg M, Bull FC: Do logbooks influence recall of physical activity in validation studies? Med $\mathrm{Sci}$ Sports Exerc 2004, 36: I 181-1 I86.

141. Verheul A-C, Prins AN, Kemper HCG, Kardinaal AFM, Van Erp-Baart M-A: Validation of a weight-bearing physical activity questionnaire in a study of bone density in girls and women. Pediatr Exerc Sci 1998, 10:.

142. Voorrips LE, Ravelli AC, Dongelmans PC, Deurenberg P, van Staveren WA: A physical activity questionnaire for the elderly. Med Sci Sports Exerc I991, 23:974-979.

143. Walsh MC, Hunter GR, Sirikul B, Gower BA: Comparison of selfreported with objectively assessed energy expenditure in black and white women before and after weight loss. Am J Clin Nutr 2004, 79: 1013-1019.

144. Wareham NJ, Jakes RW, Rennie KL, Mitchell J, Hennings S, Day NE: Validity and repeatability of the EPIC-Norfolk Physical Activity Questionnaire. Int J Epidemiol 2002, 31:168-174.

145. Warms CA, Belza BL: Actigraphy as a measure of physical activity for wheelchair users with spinal cord injury. Nurs Res 2004, 53:136-143.

146. Washburn RA, Smith KW, Jette AM, Janney CAW: The Physical Activity Scale for the Elderly (PASE): development and evaluation. J Clin Epidemiol 1993, 46:153-162.

147. Washburn RA, Ficker JL: Physical Activity Scale for the Elderly (PASE): the relationship with activity measured by a portable accelerometer. Sports Med Phys Fitness 1999, 39(4):336-340.

148. Washburn RA, Jacobsen DJ, Sonko BJ, Hill JO, Donnelly JE: The validity of the Stanford Seven-Day Physical Activity Recall in young adults. Med Sci Sports Exerc 2003, 35: I374-1380.

149. Welk G], Differding JA, Thompson RW, Blair SN, Dziura J, Hart P: The utility of the Digi-walker step counter to assess daily physical activity patterns. Med Sci Sports Exerc 2000, 32:S48I-S488.

150. Welk GJ, Thompson RW, Galper DI: A temporal validation of scoring algorithms for the 7-day physical activity recall. Meas Phys Edu Exer Sci 200I, 5:

15I. Wendel-Vos GC, Schuit AJ, Saris WH, Kromhout D: Reproducibility and relative validity of the short questionnaire to assess health-enhancing physical activity. J Clin Epidemiol 2003, 56:1163-1169.

152. Whitt MC, Dubose KD, Ainsworth BE, Tudor-Locke C: Walking patterns in a sample of African American, Native American, and Caucasian women: the Cross-Cultural Activity Participation Study. Health Educ Behav 2004, 3 I (\$ Suppl):45S-56S.

153. Wickel EE, Welk GJ, Eisenmann JC: Concurrent validation of the Bouchard Diary with an accelerometry-based monitor. Med Sci Sports Exer 2006, 38:373-379.

154. Wilbur J, Chandler P, Miller AM: Measuring adherence to a women's walking program. West J Nurs Res 200I, 23:8-24.

155. Wilkinson S, Huang CM, Walker LO, Sterling BS, Kim M: Physical activity in low-income postpartum women. J Nurs Scholarsh 2004, 36:109-114.

156. Williams E, Klesges RC, Hanson CL, Eck LH: A prospective study of the reliability and convergent validity of three physical activity measures in a field research trial. J Clin Epidemiol 1989, 42: $1161-1170$.

157. Yamamura C, Tanaka S, Futami J, Oka J, Ishikawa-Takata K, Kashiwazaki $\mathrm{H}$ : Activity diary method for predicting energy expenditure as evaluated by a whole-body indirect human calorimeter. J Nutr Sci Vitaminol 2003, 49:262-269.

158. Adams SA, Matthews CE, Ebbeling CB, Moore CG, Cunningham JE, Fulton J, Hebert JR: The effect of social desirability and social approval on self-reports of physical activity. Am J Epidemiol 2005, I $61: 389-398$. 
159. Ainsworth BE, Jacobs DR Jr, Leon AS, Richardson MT, Montoye HJ: Assessment of the accuracy of physical activity questionnaire occupational data. J Occup Med 1993, 35: I017-1027.

160. Barnard JA, Tapsell LC, Davies PS, Brenninger VL, Storlien LH: Relationship of high energy expenditure and variation in dietary intake with reporting accuracy on 7 day food records and diet histories in a group of healthy adult volunteers. Eur J Clin Nutr 2002, 56:358-367.

16I. Boulay MR, Serresse O, Almeras N, Tremblay A: Energy expenditure measurement in male cross-country skiers: comparison of two field methods. Med Sci Sports Exer 1994, 26:248-253.

162. Clark D, Tomas F, Withers RT, Chandler C, Brinkman M, Phillips J, Berry M, Ballard FJ, Nestel P: Energy metabolism in free-living, 'large-eating' and 'small-eating' women: studies using 2H2( I 8)O. Br J Nutr 1994, 72:2I-3I.

163. Davis JN: Comparisons of physical activity and dietary components in an overweight/obese population and their normal weight controls matched for gender, age and height. In PhD Thesis The University of Texas at Austin; 2004.

164. Fogelholm M, Hiilloskorpi H, Laukkanen R, Oja P, Van Marken LW, Westerterp K: Assessment of energy expenditure in overweight women. Med Sci Sports Exerc 1998, 30: I 191-II97.

165. Jakicic JM, Polley BA, Wing RR: Accuracy of self-reported exercise and the relationship with weight loss in overweight women. Med Sci Sports Exerc 1998, 30:634-638.

166. Johnson-Kozlow M, Sallis JF, Gilpin EA, Rock CL, Pierce JP: Comparative validation of the IPAQ and the 7-day PAR among women diagnosed with breast cancer. Int J Behav Nutr Phys Act 2006, 3:7.

167. Koulouri AA, Tigbe WW, Lean ME: The effect of advice to walk 2000 extra steps daily on food intake. J Human Nutr Diet 2006, 19:263-266.

168. Levin S, Jacobs DR Jr, Ainsworth BE, Richardson MT, Leon AS: Intraindividual variation and estimates of usual physical activity. Ann Epidemiol 1999, 9:481-488.

169. Lovejoy JC, Champagne CM, Smith SR, de JL, Xie H: Ethnic differences in dietary intakes, physical activity, and energy expenditure in middle-aged, premenopausal women: the Healthy Transitions Study. Am J Clin Nutr 200I, 74:90-95.

170. Masse LC, Fulton JE, Watson KL, Heesch KC, Kohl HW III, Blair SN, Tortolero SR: Detecting bouts of physical activity in a field setting. Res $Q$ Exerc Sport 1999, 70(3):212-219.

I7I. Miller CL: A symptom management intervention in diabetic coronary artery bypass graft patients. In PhD Thesis University of Nebraska Medical Center; 2005.

172. Racette SB, Schoeller DA, Kushner RF: Comparison of heart rate and physical activity recall with doubly labeled water in obese women. Med Sci Sports Exerc 1995, 27:126-133.

173. Richardson MT, Leon AS, Jacobs DR Jr, Ainsworth BE, Serfass R: Ability of the Caltrac accelerometer to assess daily physical activity levels. J Cardiopulm Rehabil 1995, I 5: I07-II3.

174. Seale JL, Klein G, Friedmann J, Jensen GL, Mitchell DC, SmiciklasWright $\mathrm{H}$ : Energy expenditure measured by doubly labeled water, activity recall, and diet records in the rural elderly. Nutr 2002, I 8:568-573.

175. Sjostrom M, Yngve A, Ekelund U, Poortvliet E, Hurtig-Wennlof A, Nilsson A, Hagstromer M, Nylund K, Faskunger J: Physical activity in groups of Swedish adults: Are the recommendations feasible? Scand J Nutr 2002, 46:

176. Soundy A, Taylor A: Comparison of self-reported physical activity and accelerometer-generated data in individuals with severe mental illness. J Sports Sci 2005, 23: I223-I 224.

177. Starling RD, Matthews DE, Ades PA, Poehlman ET: Assessment of physical activity in older individuals: a doubly labeled water study. J Appl Physiol 1999, 86:2090-2096.

178. Staten LK, Taren DL, Howell WH, Tobar M, Poehlman ET, Hill A, Reid PM, Ritenbaugh C: Validation of the Arizona Activity Frequency Questionnaire using doubly labeled water. Med Sci Sports Exer 2001, 33:1959-1967.

179. Stein AD, Rivera JM, Pivarnik JM: Measuring energy expenditure in habitually active and sedentary pregnant women. Med Sci Sports Exerc 2003, 35: |44|-1446.

180. Tzetzis G, Avgerinos A, Vernadakis N, Kioumourtzoglou E: Differences in self-reported perceived and objective measures of duration and intensity of physical activity for adults in skiing. Eur J Epidemiol 2001, I 7:217-222.
181. Wadsworth D: Evaluation of a social cognitive theory based email intervention to increase physical activity of college females. Dissertation Abstracts International: Section B: The Sciences and Engineering 2006, 66:4766.

182. Buchowski MS, Townsend KM, Chen KY, Acra SA, Sun M: Energy expenditure determined by self-reported physical activity is related to body fatness. Obes Res 1999, 7:23-33.

183. Liu B, Woo J, Tang N, Ng K, Ip R, Yu A: Assessment of total energy expenditure in a Chinese population by a physical activity questionnaire: examination of validity. Int J Food Sci Nutr 2001, 52:269-282.

184. Lof M, Hannestad U, Forsum E: Assessing physical activity of women of childbearing age. Ongoing work to develop and evaluate simple methods. Food Nutr Bull 2002, 23:30-33.

185. Lof M, Forsum E: Activity pattern and energy expenditure due to physical activity before and during pregnancy in healthy Swedish women. Br J Nutr 2006, 95:296-302.

186. Macfarlane DJ, Lee CC, Ho EY, Chan KL, Chan DT: Reliability and validity of the Chinese version of IPAQ (short, last 7 days). J Sci Med Sport 2007, 10:45-5I

187. Richardson MT: Evaluation of the Minnesota Leisure Time Physical Activity Questionnaire. In PhD Thesis University of Minnesota; |99|.

188. Warms CA: Acceptability and feasibility of a lifestyle physical activity program for people with spinal cord injury (SCI): A pilot study. In PhD Thesis University of Washington; 2002.

189. Blair SN, Haskell WL, Ho Ping, Paffenbarger RSJR, Vranizan KM, Farquhar JW, Wood PD: Assessment of habitual physical activity by a seven day recall in a community survey and controlled experiments. Am J Epidemiol 1985, I 22:794-804.

190. Adams SA, Matthews CE, Ebbeling CB, Moore CG, Cunningham JE, Fulton J, Hebert JR: The effect of social desirability and social approval on self-reports of physical activity. [erratum appears in Am J Epidemiol. 2005 May I; I 6 I(9):899]. AM J EPIDEMIOL 2005, I 6 I:389-398.

I9I. Bland JM, Altman DG: Statistical methods for assessing agreement between two methods of clinical measurement. Lancet 1986, I(8476):307-310.

192. Ainsworth BE, Haskell WL, Whitt MC, Irwin ML, Swartz AM, Strath S), O'Brien WL, Bassett DR Jr, Schmitz KH, Emplaincourt PO, et al.: Compendium of Physical Activities: an update of activity codes and MET intensities. Med Sci Sports Exer 2000, 32:S498-S5 I6.

193. Tudor-Locke CE, Myers AM, Tudor-Locke CE, Myers AM: Challenges and opportunities for measuring physical activity in sedentary adults. Sports Med 2001, 31:91-100.

194. Schoeller DA: Recent Advances from Application of Doubly Labeled Water to Measurement of Human Energy Expenditure. J Nutr 1999, I 29:1765-1768.

195. Troiano RP, Berrigan D, Dodd K, Masse LC, Tilert T, McDowell M: Physical activity in the United States measured by accelerometer. Med Sci Sports Exerc 2008, 40:181-I88.

196. Ferrari $P$, Friedenreich $C$, Matthews $C E$ : The role of measurement error in estimating levels of physical activity. $A m \mathrm{~J} \mathrm{Epi-}$ demiol 2007, 166:832-840.

Publish with Bio Med Central and every scientist can read your work free of charge

"BioMed Central will be the most significant development for disseminating the results of biomedical research in our lifetime. "

Sir Paul Nurse, Cancer Research UK

Your research papers will be:

- available free of charge to the entire biomedical community

- peer reviewed and published immediately upon acceptance

- cited in PubMed and archived on PubMed Central

- yours - you keep the copyright 